\title{
Experimental Investigation and Analysis of Dynamic Buckling of Drill String in Horizontal Well
}

\author{
Fushen Ren, Baojin Wang, Lei Zhao, and Anhe Zhu \\ School of Mechanical Science and Engineering, Northeast Petroleum University, Daqing, Heilongjiang 163318, China \\ Correspondence should be addressed to Fushen Ren; renfushen@126.com
}

Received 26 June 2017; Revised 14 October 2017; Accepted 23 October 2017; Published 22 November 2017

Academic Editor: Salvatore Russo

Copyright (C) 2017 Fushen Ren et al. This is an open access article distributed under the Creative Commons Attribution License, which permits unrestricted use, distribution, and reproduction in any medium, provided the original work is properly cited.

\begin{abstract}
Buckling of tubulars has been the subject of many researches in the past. However, the models in previous research always followed the same assumptions: the friction and rotation effects are ignored. The assumptions are relatively far from the reality. This paper focuses on the rotational drill string in horizontal well. The differential equation of the dynamic buckling is established considering some various factors, including friction, the drill string-borehole interaction, and rotation, and the equations of the critical load of the sinusoidal buckling and the spiral buckling are derived. Furthermore, the friction curve of the drill string and the critical load of the dynamic buckling during rotation are obtained. In addition, the influence of the rotational speed on the dynamic buckling and the axis orbit of the dynamic buckling are also gained. The results show that the critical load of the sinusoidal buckling has nothing to do with the rotational speed while the amplitude and the frequency of the dynamic buckling become larger with the increase of the rotational speed, and the dynamic buckling presents a completely different state with the development of the axial load at different speed ranges.
\end{abstract}

\section{Introduction}

The buckling of compressed sections of the drill string is typical in extended reach drilling and horizontal well. With the expansion of the application range of horizontal well, the buckling problem of drill string confined in horizontal well is more and more prominent. Buckling can intensify the bending stress and lead to fatigue over time. More importantly, buckled shapes exert larger side forces than unbuckled which increases friction losses and can lead to the lockup of the string and the potential loss of equipment and section of the well [1-3]. The buckling includes the static buckling and the dynamic buckling. The static buckling analysis has some ideal assumptions in former researches. With the development of horizontal drilling technology, it is very important to know if the hypothesis agrees well with the actual drilling conditions. The dynamic buckling behavior is more consistent with the actual drilling environment and worthy of further research relative to the static buckling.

Lubinski et al. first proposed the drill string buckling more than half a century ago $[4,5]$. Later, Mitchell extended Lubinski's helical buckling model and solved the buckling problem by approximate analytical and numerical methods [6-10]. Gao et al. proposed a model depicting the full phase of tubular string buckling in vertical well. The general buckling configurations of the entire drill string are deduced with the suspended and continuous contact sections, respectively, depicted by beam-column model and buckling differential equation in consideration of the gravity [11-13]. Wang et al. established buckling string fatigue life prediction model with Forman fatigue life prediction model which considering stress ratio is used to predict drill string fatigue life [14]. He derived an improved formula for critical buckling forces, which takes the well curvature into account. The model predicts that the well curvature substantially affects the critical force for helical buckling [15]. Mitchell presented the large-displacement analysis of a helically buckled slender beam and predicted that shear force and twisting moment are induced in helically buckled pipe without externally applied torque [16]. Menand et al. proposed a comparison of an advanced model, ABIS model, for drill string mechanics with an experimental setup reproducing the buckling in a wellbore. The model presently estimates the critical buckling load in any drilling situation to estimate loads and stresses 


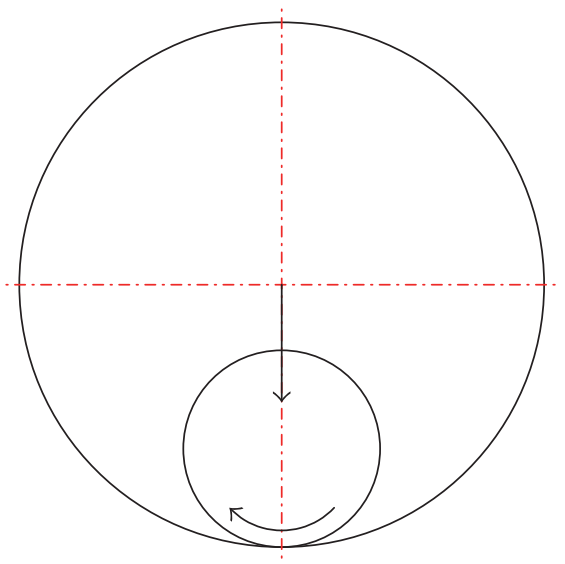

(a) Steady state

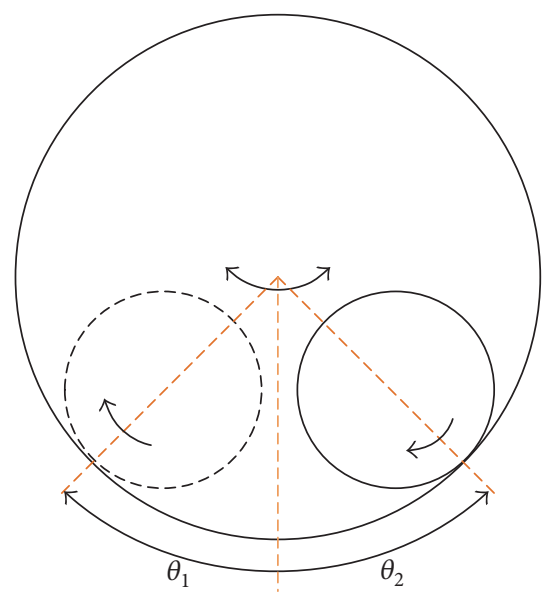

(b) Snaking motion

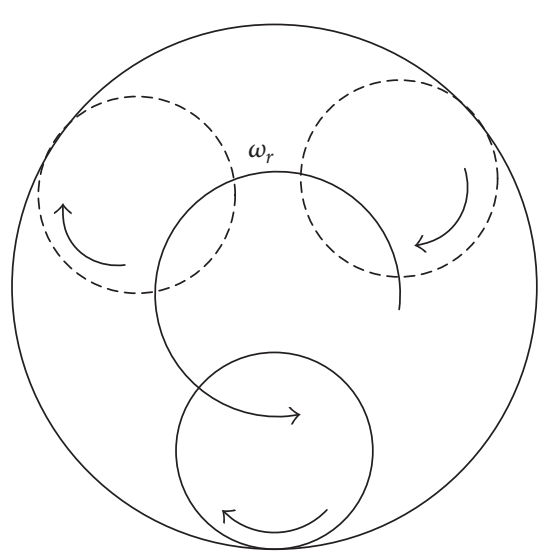

(c) Whirl

FIGURE 1: Schematic diagrams of three kinds of buckling motion.

that can be safely applied on the drill string [17]. The first buckling mode that the long cylinder will undergo is what will be termed constrained Euler sinusoidal buckling. Dawson and Paslay derived the first expression for the critical force of sinusoidal buckling for pipes in an inclined wellbore [18]. Schuh et al. presented an analysis of the influence of curvature on the critical buckling force. The author assumed Dawson's model for sinusoidal buckling as causing helical buckling, which produces very conservative calculations $[19,20]$. Paslay et al. derived an approximation solution about prebuckling mode originally using an energy method applied to a general displacement field; however, the subsequent behavior of the cylinder is not predicted. And the analysis is similar to that given by Paslay et al. [21, 22]. Qiu utilized the conservation of energy and the principle of virtual work to derive the new equations that can predict the axial compression force for a stable sinusoidal configuration. The author emphasizes the effect of initial CT configuration, or residual bending, on buckling behavior in a hole of constant curvature [23]. Qiu et al. researched the effect of residual bending on buckling load and proposed modified formulation for the onset of sinusoidal buckling [24]. Gao et al. solved frictionless equations of motion for long tubulars in horizontal well and found the configuration of bucked tubular subjected to axial and torsion loading [25]. Duman et al. experimentally researched the effect of tool joints on sinusoidal buckling load. The results show that the sinusoidal buckling load is not affected by the presence of tool joints significantly [26, 27]. Weltzin et al. conducted experiments on buckling. The authors applied a high accuracy continuous gyro to measure the drill string geometry changes as a function of axial load. Their measurements showed that, even at zero WOB, friction force cannot be neglected in case of sinusoidal buckling due to local irregularities in the well path. They also showed that the nonuniform stiffness effect of tool joints at high WOBs can produce frictions to cause lockup even before helical buckling [28-30]. There are many studies on the static stability analysis of the drill string in horizontal well, deviated well, vertical well, and curved well, but there are few researches on the dynamic buckling of the rotational drill string, even though most studies of the dynamic buckling behavior in the existing literatures are aimed at the vertical well, and the nonlinear influence of the various deformation is not considered along with neglecting the influence of friction resistance.

In this paper, the self-weight of the drill string, the drill string-borehole interaction, the tangential friction between the rotational drill string and the borehole wall, and different rotational speeds are taken into account. How to integrate the various boundary conditions into the mathematical model is the major difficulty confronted by the authors. The dynamic buckling model is established after sufficiently considering the various factors, and then the perturbation solution of the model is obtained through employing the principle of minimum potential energy.

\section{Physical Description}

The buckling behavior of the rotational drill string in horizontal well is affected by many factors. The buckling deformation along with the axial, torsional, and lateral vibrations can be caused due to the dynamic load. In the critical state, the drill string will lose its stability, and the snaking motion appears. With the increase of rotational speed or the load, the whirl motion even occurs with the buckling configuration. The schematic diagrams of three kinds of buckling motion of the rotational drill string are shown in Figure 1.

The buckling movement of the drill string may occur in different states during drilling due to different drilling parameters, such as axial load and rotational speed. Three kinds of buckling motion with different rotational speed are revealed in Figure 2, among which the left side is the top view and the right side is the axial view.

The buckling motion is shown in Figure 2(a) when the rotational speed is $\omega_{1}$. The drill string in horizontal well is at a stable equilibrium status. The drill string rotates around 

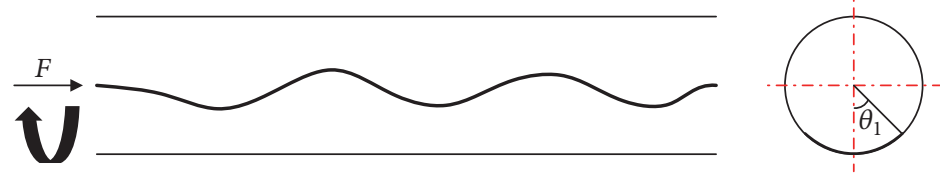

(a) Rotational speed $\omega_{1}$
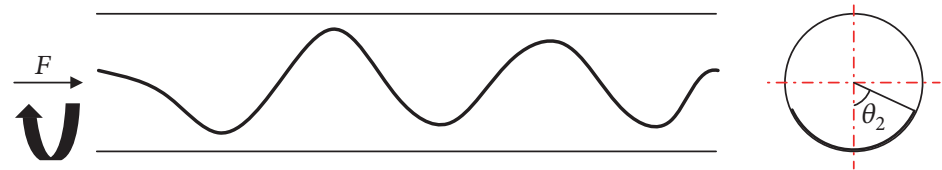

(b) Rotational speed $\omega_{2}$
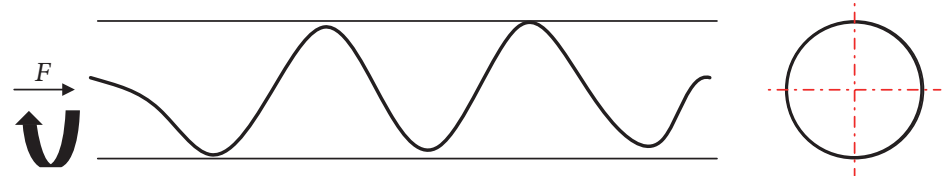

(c) Rotational speed $\omega_{3}$

FIGURE 2: Schematic diagrams of dynamic physical buckling.

its own axis, and a slight periodic vibration occurs around the center of the drill string axis at the same time. The buckling deformation is shown in Figure 2(b) when the rotational speed is $\omega_{2}$. The snakelike movement is obvious at this time, and the drill string rotates around its axis with the severe periodic vibration. The movement of the drill string in horizontal well is obviously changed into whirling motion when the rotational speed increases to $\omega_{3}$. The drill string rotates around its own axis and rotates around the borehole at the same time. However, the whirling speed is not a constant that decreases when the drill string moves upward and increases when it moves downward.

\section{Mathematical Model}

The drill string constrained by the borehole moves mainly in the bottom of the borehole because of its own gravity. In order to analyze the dynamic buckling characteristics of the drill string in horizontal well, the drill string continuously contacted with the borehole wall, and the radial clearance is small according to the actual drilling conditions of the drill string in horizontal well. Furthermore, the drill string is elastic and has the ability to restore the initial state.

3.1. Friction. The axial displacement is produced due to the axial load during drilling. With the increase of the axial load, the lateral deformation will occur when the critical buckling load of the drill string is achieved. The spatial position of any point on the drill string can be determined by the axial displacement, radial displacement, and angular displacement. The positive direction of angular displacement is shown in Figure 1(a). The axial and radial velocity can be written as

$$
\begin{aligned}
& \vec{v}_{1}(x)=v_{1}(x) \vec{i} \\
& \vec{v}_{2}(x)=v_{2}(x) \vec{q},
\end{aligned}
$$

where $\vec{q}=\cos \theta \vec{j}+\sin \theta \vec{k} ; \vec{i}, \vec{j}$ and $\vec{k}$ are the unit vectors along $x-, y$-, and $z$-axis, respectively.

The resultant velocity can be written as

$$
\vec{v}(x)=v_{1}(x) \vec{i}+v_{2}(x) \vec{q} .
$$

$f_{1}(x)$ and $f_{2}(x)$ denote the axial and radial components of the sliding friction at the position $x$, respectively.

The following equations must be satisfied:

$$
f_{1}^{2}(x)+f_{2}^{2}(x)=f^{2}
$$

A bit of drill string $d x$ is taken out, and the mass is assumed as $d m$. According to the kinetic energy theorem, the axial and radial components of the sliding friction at the position $x$ must satisfy the following equations:

$$
\begin{aligned}
& f_{1}(x) \cdot t=d m \cdot v_{1}(x), \\
& f_{2}(x) \cdot t=d m \cdot v_{2}(x) .
\end{aligned}
$$

And the following equation can be obtained:

$$
\frac{f_{1}(x) \cdot t}{f_{2}(x) \cdot t}=\frac{d m \cdot v_{1}(x)}{d m \cdot v_{2}(x)} .
$$

After simplified, (5) can change into the following equation:

$$
\frac{f_{1}(x)}{f_{2}(x)}=\frac{v_{1}(x)}{v_{2}(x)} .
$$

Then the following equation can be yielded:

$$
\begin{aligned}
& f_{1}(x)=\frac{\left|v_{1}(x)\right| f}{\sqrt{v_{1}^{2}(x)+v_{2}^{2}(x)}}, \\
& f_{2}(x)=\frac{\left|v_{2}(x)\right| f}{\sqrt{v_{1}^{2}(x)+v_{2}^{2}(x)}} .
\end{aligned}
$$




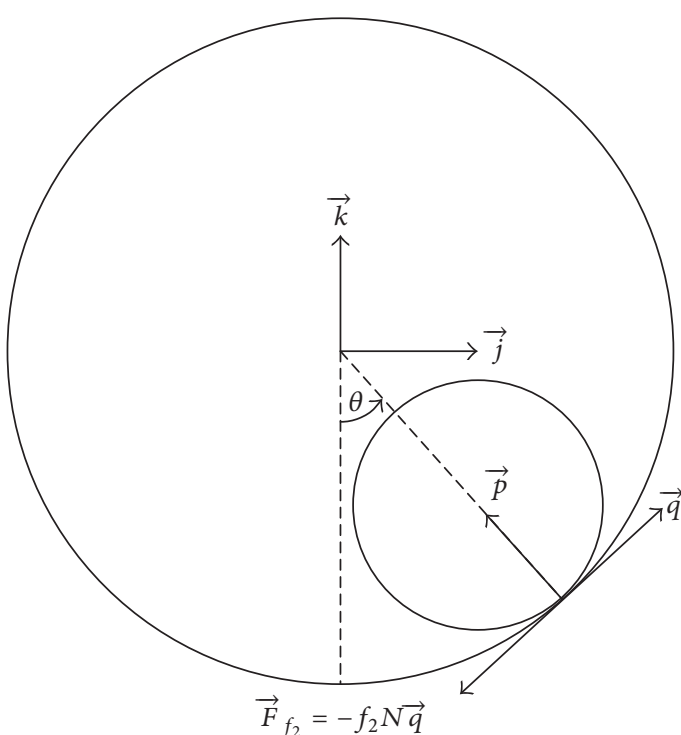

(a)

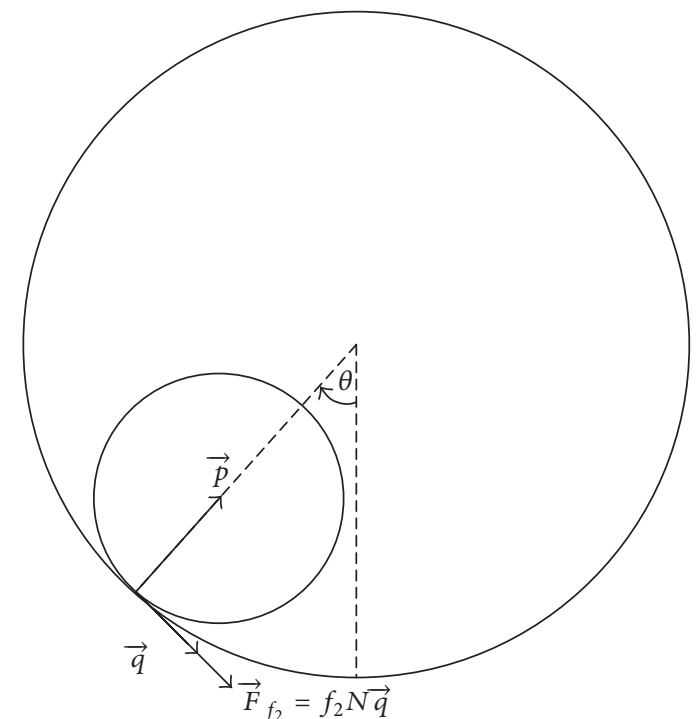

(b)

FIGURE 3: Direction of tangential friction.

It is generally assumed that the drill string is sliding on the borehole wall. Let $\theta(x)>0$ when the drill string slides up to the right side just as shown in Figure 3(a). The direction of the transverse friction $\vec{F}_{f_{2}}=-f_{2} N \vec{q}$ is opposite to that of $\vec{q}=\cos \theta \vec{j}+\sin \vec{\theta} \vec{k}$. However, if the drill string slides up to the left side, the direction of the transverse friction is the same as that of $\vec{q}$. And the transverse friction is $\vec{F}_{f_{2}}=f_{2} N \vec{q}$ just as shown in Figure 3(b).

3.2. Dynamic Buckling Equation. $u_{x}(x, t)$ and $\theta(x, t)$ denote the axial displacement and the angular displacement of any point on the drill string, respectively. $u_{x}(x, t)$ is composed of two parts including the axial deformation due to axial load and the displacement caused by transverse deformation. The relationship can be expressed as

$$
\begin{aligned}
u_{x}(x, t) & =u_{a}(x, t)+u_{b}(x, t), \\
-E A \frac{\partial u_{a}}{\partial x} & =F(x, t)-\mu N \frac{\partial \theta}{\partial x}, \\
u_{b} & =\int_{0}^{x} \frac{1}{2} k_{r} r d x,
\end{aligned}
$$

where $k_{r}=-r(\partial \theta / \partial x)^{2}$ is the projections of $k \vec{n}$ into $\vec{p}$ and $r$ denotes radial displacement.

Thus, the displacement caused by the lateral bending can be expressed as

$$
u_{b}=\int_{0}^{x} \frac{1}{2} k_{r} r d x=-\frac{1}{2} r^{2} \int_{0}^{x}\left(\frac{\partial \theta}{\partial x}\right)^{2} d x .
$$

Then, the axial load can be written as

$$
F(x, t)=-E A \frac{\partial u_{x}}{\partial x}-\frac{1}{2} E A r^{2}\left(\frac{\partial \theta}{\partial x}\right)^{2},
$$

where $A$ is the cross-sectional area of the drill string; $R_{p}$ and $r_{p}$ denote the outer and the inner diameter of the drill string, respectively.

The relationship between the bending moment and the bending deformation is given by

$$
\vec{M}(x, t)=-E I k \vec{b}
$$

where $k=\sqrt{k_{r}{ }^{2}+k_{\theta}{ }^{2}}, k_{r}=-r(\partial \theta / \partial x)^{2}$, and $k_{\theta}=r\left(\partial^{2} \theta / \partial x^{2}\right)$ are the projections of $\overrightarrow{k n}$ into $\vec{p}$ and $\vec{q}$, respectively.

Substituting $k \vec{b}$ into $\vec{M}(x, t)$, so the moment vector can be obtained:

$$
\vec{M}(x, t)=\operatorname{EIr}\left[\frac{\partial^{2} \theta}{\partial x^{2}} \vec{p}+\left(\frac{\partial \theta}{\partial x}\right)^{2} \vec{q}\right]
$$

where $\vec{p}=\sin \theta \vec{j}-\cos \theta \vec{k} ; \vec{q}=\cos \theta \vec{j}+\sin \theta \vec{k} ; I$ is the moment of inertia of the drill string.

The linear momentum and angular momentum of a small section of the drill string $d x$ can be expressed as

$$
\begin{aligned}
& \vec{P}(x, t)=m_{p} \vec{v}(x, t) d x, \\
& \vec{J}(x, t)=\left[m_{p} \vec{r} \times \vec{v}+I_{p} \omega \vec{\tau}\right] d x,
\end{aligned}
$$

where $\vec{v}(x, t)=\left(\partial u_{x} / \partial t\right) \vec{i}+r(\partial \theta / \partial t) \vec{q} ; \omega$ denotes the rotational speed of the drill string; $m_{p}$ is the mass of $d x ; I_{p}$ is the moment of inertia of $d x$. 
The vector relationships between the axial load and the linear and angular velocity are expressed as follows according to the angular momentum theory.

$$
\begin{array}{r}
\frac{\partial \vec{F}}{\partial x}-\vec{f}+m_{p} \frac{\partial \vec{v}}{\partial t}=0 \\
\frac{\partial \vec{M}}{\partial x}+\vec{\tau} \times \vec{F}+I_{p} \omega r\left(\frac{\partial^{2} \theta}{\partial x \partial t} \vec{q}-\frac{\partial \theta}{\partial x} \frac{\partial \theta}{\partial t} \vec{p}\right)=0 .
\end{array}
$$

The dynamic buckling equation of the drill string constrained by borehole wall can be obtained from (10), (12), and (14).

$$
\begin{aligned}
& E A \frac{\partial^{2} u_{x}}{\partial x^{2}}-m_{p} \frac{\partial^{2} u_{x}}{\partial t^{2}}+E A r^{2} \frac{\partial \theta}{\partial x} \frac{\partial^{2} \theta}{\partial x^{2}}=0 \\
& E I r\left[\frac{\partial^{4} \theta}{\partial x^{4}}-6\left(\frac{\partial \theta}{\partial x}\right)^{2} \frac{\partial^{2} \theta}{\partial x^{2}}\right] \\
& \quad+r \frac{\partial}{\partial x}\left[F_{x} \frac{\partial \theta}{\partial x}-\mu N \frac{\partial^{2} \theta}{\partial x^{2}}\right]-\mu N \frac{\partial \theta}{\partial x} \\
& \quad+I_{p} \omega\left(\frac{\partial \omega_{r}}{\partial x}-\omega_{\theta} \frac{\partial \theta}{\partial x}\right)+m_{p} g \sin \theta+m_{p} r \frac{\partial^{2} \theta}{\partial t^{2}}=0 \\
& N_{r}-E^{2}\left[\left(\frac{\partial \theta}{\partial x}\right)^{4}-3\left(\frac{\partial^{2} \theta}{\partial x^{2}}\right)^{2}-4 \frac{\partial \theta}{\partial x} \frac{\partial^{3} \theta}{\partial x^{3}}\right] \\
& \quad+\left(F_{x}-\mu N\right) r\left(\frac{\partial \theta}{\partial x}\right)^{2}+I_{p} \omega\left(\frac{\partial \omega_{\theta}}{\partial x}-\omega_{r} \frac{\partial \theta}{\partial x}\right) \\
& \quad+m_{p} g \cos \theta+m_{p} r\left(\frac{\partial \theta}{\partial t}\right)^{2}=0 .
\end{aligned}
$$

Converting (16) and (17) into proper dimensionless indexes, then the speed and period are obtained.

$$
\begin{aligned}
v^{2} & =\omega^{2}\left[\left(a_{\max }^{2}-1\right)^{2}-\left(a^{2}-1\right)^{2}\right] \\
& =\omega^{2}\left(a_{\max }^{2}+a^{2}-2\right)\left(a_{\max }^{2}-a^{2}\right), \\
T & =\frac{2 \varepsilon}{\omega a_{\max }} K\left[\frac{\sqrt{2\left(a_{\max }^{2}-1\right)}}{a_{\max }}\right],
\end{aligned}
$$

where $v$ is the linear velocity of the drill string; $a$ and $T$ are the amplitude and period of the dynamic buckling, respectively; $a_{\max }$ is the maximum amplitude of the dynamic buckling. Therefore, it is shown that the amplitude of the dynamic buckling is positively correlated with the angular velocity of the drill string while the period of the dynamic buckling is inversely related to the angular velocity of the drill string.

\section{Critical Load of Buckling Behavior}

4.1. Critical Load of Sinusoidal Buckling. Equations (20)-(22) can describe the configuration of sinusoidal buckling.

$$
\begin{aligned}
& x=r \cos \theta, \\
& y=r \sin \theta, \\
& \theta=a \sin \left(\frac{2 \pi z}{p}\right),
\end{aligned}
$$

where $r$ is the radial displacement.

The total potential energy is given by

$$
\Pi=U_{a}+U_{b}+U_{g}
$$

where $U_{a}, U_{b}$, and $U_{g}$ are the work due to the lateral bending or buckling, the elastic deformation, and the gravity, respectively. And they can be given by

$$
\begin{aligned}
U_{a} & =\frac{1}{2} r \int_{0}^{L} F k_{r} d x=-\frac{1}{2} r^{2} \int_{0}^{L} F\left(\frac{d \theta}{d x}\right)^{2} d x, \\
U_{b} & =\frac{E I}{2} \int_{0}^{L} k^{2} d x \\
& =\frac{E I r^{2}}{2} \int_{0}^{L}\left[\left(\frac{d^{2} \theta}{d x^{2}}\right)^{2}+\left(\frac{d \theta}{d x}\right)^{4}\right] d x, \\
U_{g} & =q r L,
\end{aligned}
$$

where $L$ is the length of the drill string.

Substituting the first-order differential and second-order differential of (22) into (23), the total potential energy is given by

$$
\begin{aligned}
\Pi= & \frac{E I L r^{2}}{2}\left[\frac{3}{8}\left(\frac{2 \pi}{p}\right)^{4} a^{4}+\frac{1}{2}\left(\frac{2 \pi}{p}\right) a^{2}\right] \\
& -\frac{F L r^{2}}{2}\left[\frac{1}{2}\left(\frac{2 \pi}{p}\right) a^{2}\right]+\frac{q r L}{2}\left[\frac{1}{2} a^{2}\right] \\
& -\frac{q r L}{24}\left[\frac{3}{8} a^{2}\right] .
\end{aligned}
$$

The first-order differential of (25) is written as

$$
\begin{gathered}
\delta \Pi=\frac{\partial \Pi}{\partial a} \delta a=\left[\frac{E I L r^{2}}{2}\left(\frac{2 \pi}{p}\right)^{4}\left(\frac{3}{8} a^{3}+a\right)\right. \\
\left.-\frac{F_{b} L r^{2}}{2}\left(\frac{2 \pi}{p}\right)^{2} a+\frac{q r L a}{2}-\frac{q r L}{16} a^{3}\right] \delta a .
\end{gathered}
$$

Equation (26) is equal to zero, and the axial load of the equilibrium state is given by

$$
F=\frac{4 \pi^{2} E I}{p^{2}}\left(\frac{3}{2} a^{2}+1\right)+\frac{q}{4 \pi^{2} r}\left(1-\frac{a^{2}}{8}\right) p^{2} .
$$


Let $\partial F / \partial p=0$, and the wavelength of sinusoidal buckling is given by

$$
p=2 \pi \sqrt[4]{\frac{E I r\left((3 / 2) a^{2}+1\right)}{q\left(1-a^{2} / 8\right)}} .
$$

Substituting (28) into (27), the relationship between the axial load and the buckling amplitude is obtained:

$$
F=2 \sqrt{\frac{E I q\left(1.5 a^{2}+1\right)\left(1-0.125 a^{2}\right)}{r}} .
$$

The critical load of the sinusoidal buckling is obtained when $a=0$.

$$
F_{\mathrm{cr}}=2 \sqrt{\frac{E I q}{r}} .
$$

The second-order differential formula of (18) is expressed as

$$
\begin{aligned}
\delta^{2} \Pi & =\left[\frac{E I L r^{2}}{2}\left(\frac{2 \pi}{p}\right)\left(\frac{9}{2} a^{2}+1\right)-\frac{F_{b} L r^{2}}{2}+\frac{q r L}{2}\right. \\
& \left.-\frac{3 q r L}{16} a^{2}\right] \delta a^{2} .
\end{aligned}
$$

Substituting (27) and (28) into (30), the second-order differential form of total potential energy is expressed by

$$
\begin{aligned}
\delta^{2} \Pi & =\left[\frac{E I L r^{2}}{2}\left(\frac{2 \pi}{p}\right)\left(\frac{9}{2} a^{2}+1\right)-\frac{F_{b} L r^{2}}{2}+\frac{q r L}{2}\right. \\
& \left.-\frac{3 q r L}{16} a^{2}\right] \delta a^{2} .
\end{aligned}
$$

The critical point of the drill string to lose the steady state is obtained when $13 /\left(3 a^{2}+2\right)-1=0$. The wavelength and the maximum axial load of the sinusoidal buckling are written as

$$
\begin{aligned}
& p^{*}=2 \pi \sqrt{\frac{12 E I}{q}} \\
& F^{*}=13 \sqrt{\frac{E I q}{12 r}} \approx 3.75 \sqrt{\frac{E I q}{r}} .
\end{aligned}
$$

The drill string has not yet buckled when the axial load is less than $F_{\mathrm{cr}}$. The sinusoidal buckling of the drill string is instability when the axial load is $F^{*}$.

4.2. Critical Load of Spiral Buckling. The potential energy of the bending deformation of the spiral buckling is expressed as

$$
U_{b}=\frac{1}{2} \int_{0}^{L} E I\left[\left(x^{\prime \prime}\right)^{2}+\left(y^{\prime \prime}\right)^{2}\right] d z .
$$

The work done by the gravity of the drill string is given by

$$
\begin{aligned}
W_{q} & =\operatorname{qrL}\left(1-\cos \frac{2 \pi z}{p_{h}}\right) d z \\
& \approx q r\left(L-\frac{\bar{p}_{h}}{2 \pi} \sin \frac{2 \pi L}{\bar{p}_{h}}\right),
\end{aligned}
$$

where $p_{h}$ is the screw pitch of the buckling and $L$ is a multiple of $p_{h}$.

The work done by the axial load, the potential energy, and the gravity should match the functional principle.

$$
\int_{0}^{\delta} F(\delta) d \delta=U_{b}+W_{q} .
$$

The relationship between the axial load and the displacement is given by

$$
\frac{1}{2} F \delta=\frac{8 \pi^{4} E I r^{2} L}{p^{4}}+q r L .
$$

The axial shortening of the drill string is given by

$$
\delta=L\left(1-\frac{p}{\sqrt{p^{2}+4 \pi^{2} r^{2}}}\right) \approx \frac{4 \pi^{2} r^{2} L}{p^{2}} .
$$

Substituting (38) into (37), the axial load is obtained as

$$
F=\frac{8 \pi^{2} E I}{p^{2}}+\frac{q}{\pi^{2} r} p^{2}
$$

The wavelength of the spiral buckling is obtained when $\partial F / \partial p=0$

$$
p=\pi \sqrt[4]{\frac{8 E I r}{q}} .
$$

Substituting (40) into (39), the minimum critical load of the spiral buckling of the drill string is obtained as

$$
F_{\text {hel }}=3 \sqrt{\frac{2 E I q}{r}} \approx 4.24 \sqrt{\frac{E I q}{r}},
$$

where $F_{\text {hel }}$ is the minimum critical load of the spiral buckling.

The spiral buckling of the drill string occurs when the axial load is greater than $F_{\text {hel }}$. The drill string is situated between the sinusoidal buckling and the spiral buckling when the axial load changes between $F^{*}$ and $F_{\text {hel }}$.

\section{Simulation and Experiment}

The experimental apparatus for the drill string under horizontal compression is investigated based on the similarity theory [31]. The schematic diagram and physical maps of the whole structure are shown in Figures 4-6. The experiment apparatus is composed of drill string, loading system, simulation downhole, precession system, measurement system, 


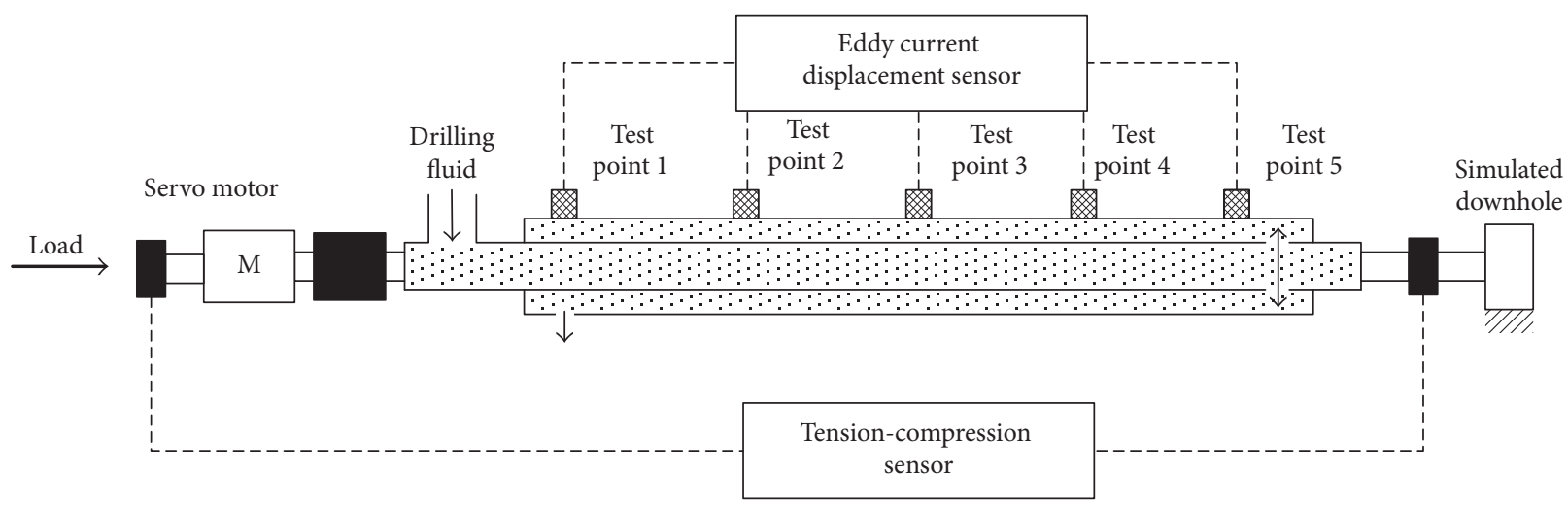

FIGURE 4: Schematic diagram of the whole structure of the experimental apparatus.

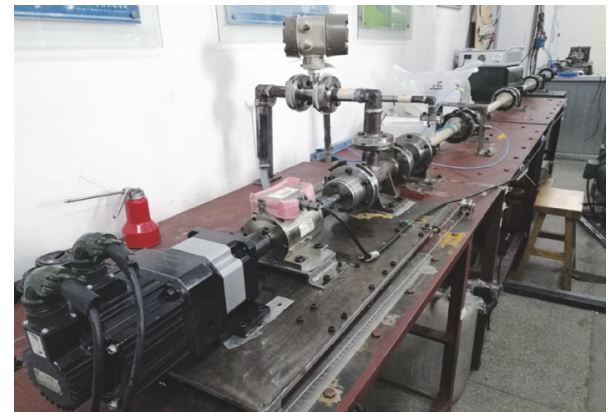

Figure 5: Experimental apparatus.

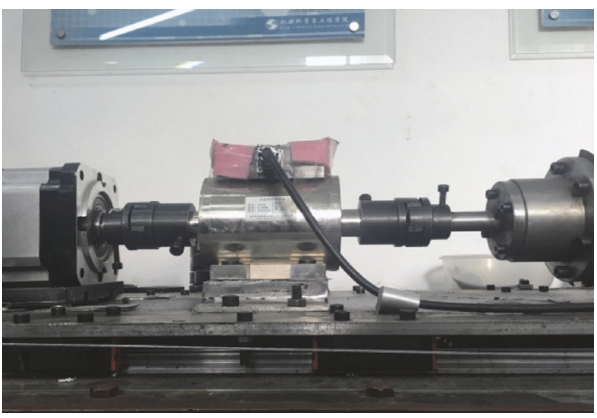

FIGURE 6: Precession system.

and cycling system. The apparatus can be used to test the dynamic characteristics of the drill string in horizontal well with different axial load, rotational speed, and the fluid-solid coupling with different fluid rate. The general solution in the physical phenomenon group is transformed into the special solution through the single value condition in the similarity theory.

The similarity criteria are deduced by the dimension analysis method. The parameters and the dimensions of the drill string can be seen in Table 1 .

According to Table 1, the dimension matrix of the horizontal drill string dynamics system can be given in Table 2.
TABLE 1: Drill string dynamics affect parameters and dimension.

\begin{tabular}{lcc}
\hline Symbol & Parameters & $\begin{array}{c}\text { Dimension } \\
\text { L-T-M system }\end{array}$ \\
\hline$a_{1}$ & Length of drill string & $\mathrm{L}$ \\
$a_{2}$ & Elastic modulus & $\mathrm{ML}^{-1} \mathrm{~T}^{-2}$ \\
$a_{3}$ & Drill string mass & $\mathrm{M}$ \\
$a_{4}$ & Drill string density & $\mathrm{ML}^{-3}$ \\
$a_{5}$ & Memento of inertial & $\mathrm{L}^{4}$ \\
$a_{6}$ & Axial force; friction; drill & $\mathrm{MT}^{-2}$ \\
$a_{7}$ & string gravity & $\mathrm{T}^{-1}$ \\
\hline
\end{tabular}

Then the following equations can be obtained from the dimension matrix:

$$
\begin{aligned}
a_{2}+a_{3}+a_{4}+a_{6} & =0, \\
a_{1}-a_{2}-3 a_{3}+4 a_{5}+a_{6} & =0, \\
-2 a_{2}-2 a_{6}-a_{7} & =0 .
\end{aligned}
$$

Solving (42), the following equation can be obtained:

$$
\begin{aligned}
& a_{1}=-3 a_{4}-4 a_{5}-2 a_{6}+a_{7}, \\
& a_{2}=-a_{6}-0.5 a_{7}, \\
& a_{3}=-a_{4}+0.5 a_{7} .
\end{aligned}
$$

Thus, the $\pi$ matrix of (43) is shown in Table 3 .

According to the $\pi$ matrix, the following equations can be obtained:

$$
\begin{aligned}
& \pi_{1}=l^{-3} \rho^{-1}=\frac{m}{l^{3} \rho}, \\
& \pi_{2}=l^{-4} I=\frac{I}{l^{4}}, \\
& \pi_{3}=l^{-2} E F=\frac{F}{l^{2} E}, \\
& \pi_{4}=l E^{-0.5} \rho^{0.5} \Omega=l \Omega \sqrt{\frac{\rho}{E}} .
\end{aligned}
$$


TABLE 2: Dimension matrix of the horizontal drill string dynamics system.

\begin{tabular}{lccccccc}
\hline & $a_{1}$ & $a_{2}$ & $a_{3}$ & $a_{4}$ & $a_{5}$ & $a_{6}$ & $a_{7}$ \\
\hline $\mathrm{M}$ & 0 & 1 & 1 & 1 & 0 & 0 & 1 \\
$\mathrm{~L}$ & 1 & -1 & -3 & 0 & 4 & 1 & 0 \\
$\mathrm{~T}$ & 0 & -2 & 0 & 0 & 0 & -2 \\
\hline
\end{tabular}

TABLE 3: $\pi$ matrix.

\begin{tabular}{lccccccc}
\hline & $a_{1}$ & $a_{2}$ & $a_{3}$ & $a_{4}$ & $a_{5}$ & $a_{6}$ \\
\hline$\pi_{1}$ & -3 & 0 & -1 & 1 & 0 & 0 & 0 \\
$\pi_{2}$ & -4 & 0 & 0 & 0 & 0 & 1 & 0 \\
$\pi_{3}$ & -2 & -1 & 0.5 & 0 & 0 & 0 \\
$\pi_{4}$ & 1 & -0.5 & 0 & 0 & 0 \\
\hline
\end{tabular}

TABLE 4: Speed of the experiment and the simulation.

\begin{tabular}{lcccccc}
\hline Rotational speed & $\Omega_{1}$ & $\Omega_{2}$ & $\Omega_{3}$ & $\Omega_{4}$ & $\Omega_{5}$ & $\Omega_{6}$ \\
\hline Simulation/(r/min) & 50 & 100 & 150 & 200 & 250 & 300 \\
Experiment/(r/min) & 17.36 & 34.72 & 53.57 & 71.43 & 89.29 & 107.14 \\
\hline
\end{tabular}

The similarity criteria are as follows:

$$
\begin{gathered}
\left(\frac{P}{l^{2} E}\right)=\left(\frac{\widehat{P}}{\widehat{l}^{2} \widehat{E}}\right), \\
\left(l \omega \sqrt{\frac{\rho}{E}}\right)=\left(\widehat{l} \widehat{\omega} \sqrt{\frac{\widehat{\rho}}{\widehat{E}}}\right) .
\end{gathered}
$$

The similarity ratio of the rotational speed is $c_{\omega}=\widehat{\omega} / \omega$ and the similarity ratio of the axial load is $c_{P}=\widehat{P} / P . \widehat{P}$ and $\widehat{\omega}$ denote the axial load and rotational speed in the experiment, respectively. $P$ and $\omega$ denote the axial load and rotational speed in the actual well field, respectively. In the experiment, $c_{\omega}=2.8$ and $c_{P}=1 / 9130$.

5.1. Parameters in the Experiment. According to the similarity theory, the parameters used in the experiment and the actual well field are shown in Table 4. The simulation conducted in this paper adopts the parameters used in the actual well field.

\subsection{Transfer Efficiency of the Axial Load. The curve between} the loading and the receiving force from the sensors can be obtained. The curves of the static axial load and dynamic axial load are shown in Figures 7 and 8.

The load from the receiving end increases with loading and reduces with unloading, whether the drill string is rotary or not. The difference between the two curves in the initial stage is small, and, with the increase of the load, the difference between the two curves increases. Thus, the friction resistance increases. The load from the receiving end produces a delay as unloading, and the horizontal segment in the curve appears. Moreover, the two curves in the loading and unloading process are getting closer and closer with the development of the rotational speed, showing that the axial load transfer efficiency is higher and higher. Meanwhile, the vibrating frequency of the drill string buckling is increasing.

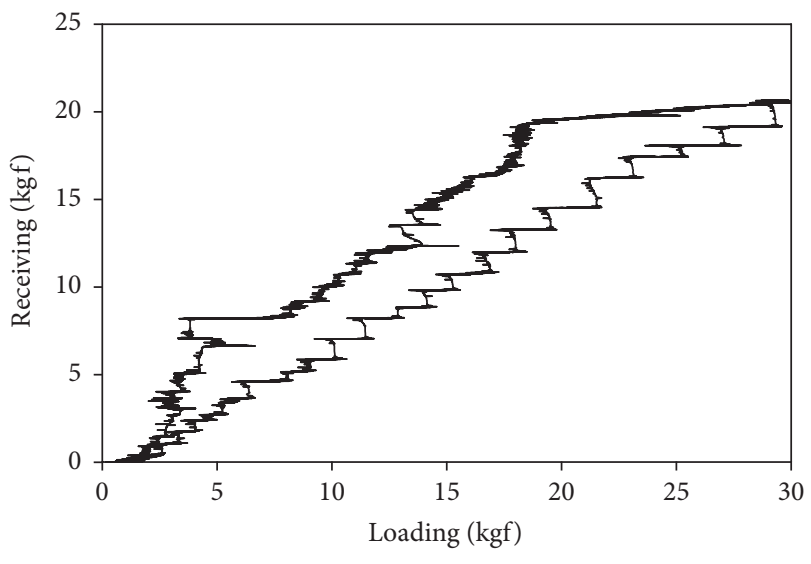

Figure 7: Static axial load.

The higher frequency vibration will significantly shorten the life of the drill string; however, reducing rotational speed is weighted against improving the transmission efficiency of the axial load. Therefore, the appropriate rotational speed should be chosen in the actual drilling. It is found that the rotational speed should be limited within a reasonable range $(60 \mathrm{r} / \mathrm{min}-90 \mathrm{r} / \mathrm{min})$ in the actual drilling. Then a better transfer efficiency and stability can be achieved.

5.3. Friction and Critical Buckling Load. The buckling deformation and even self-locking of the drill string in the borehole can lead to the failure of the drilling in horizontal well. Therefore, it is of great engineering significance to study the critical buckling load of the drill string. In the presented researches, it is assumed that the drill string does not rotate in general buckling model, and the friction resistance is opposite to the drilling direction. However, the friction resistance is determined by the rotation direction of the drill string. Mitchell [10] pointed out that the critical buckling load of 


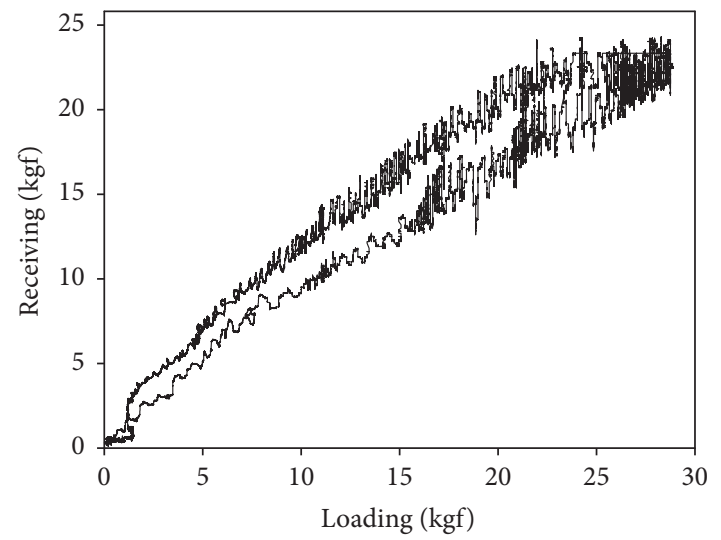

(a) $50 \mathrm{r} / \mathrm{min}$

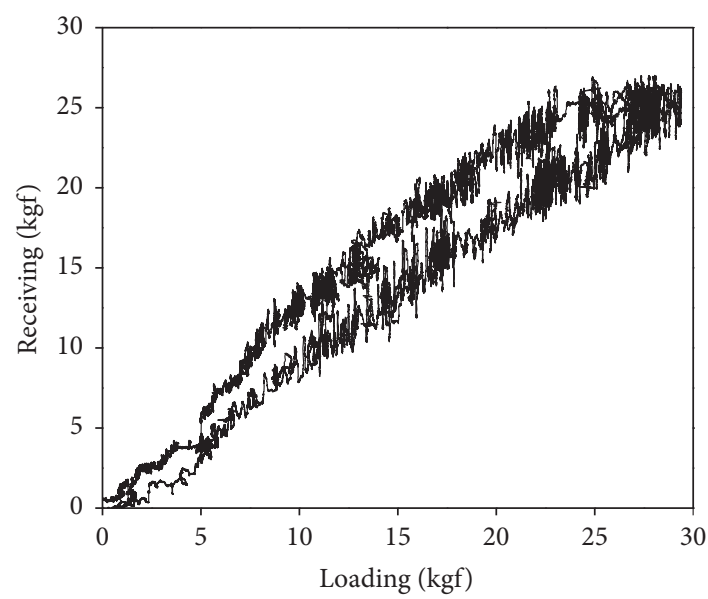

(c) $150 \mathrm{r} / \mathrm{min}$

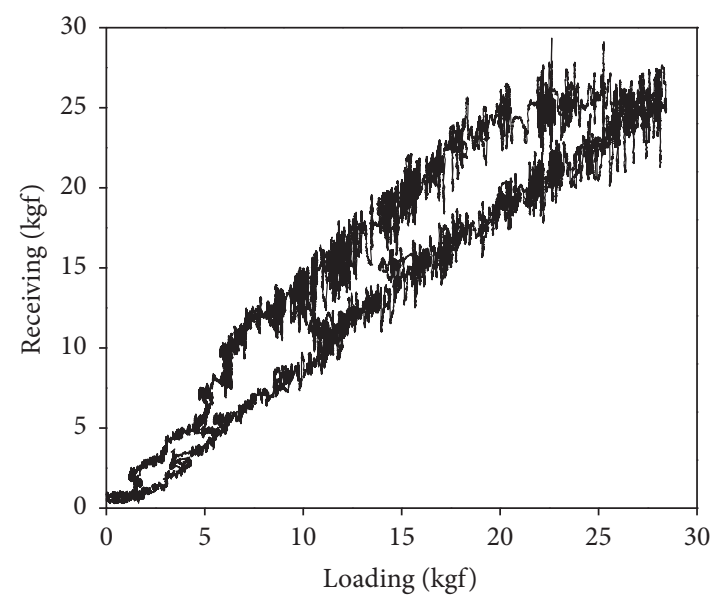

(e) $250 \mathrm{r} / \mathrm{min}$

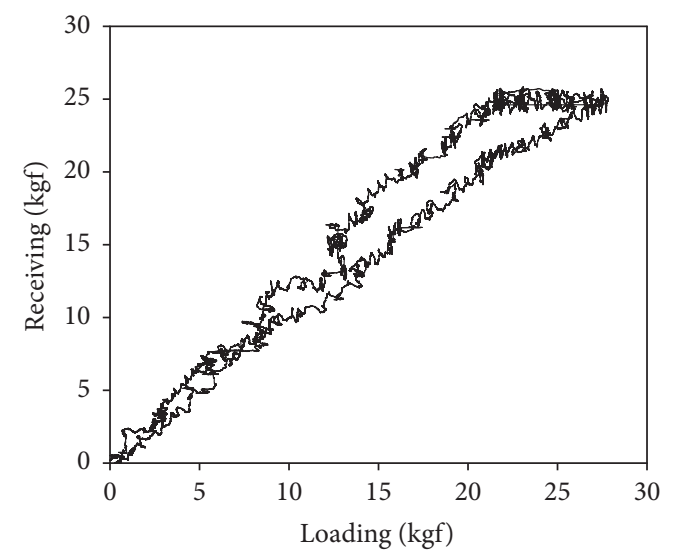

(b) $100 \mathrm{r} / \mathrm{min}$

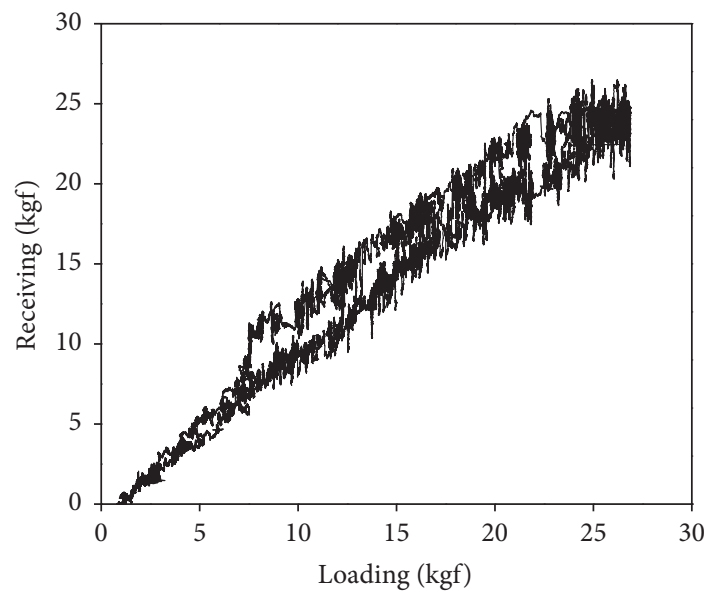

(d) $200 \mathrm{r} / \mathrm{min}$

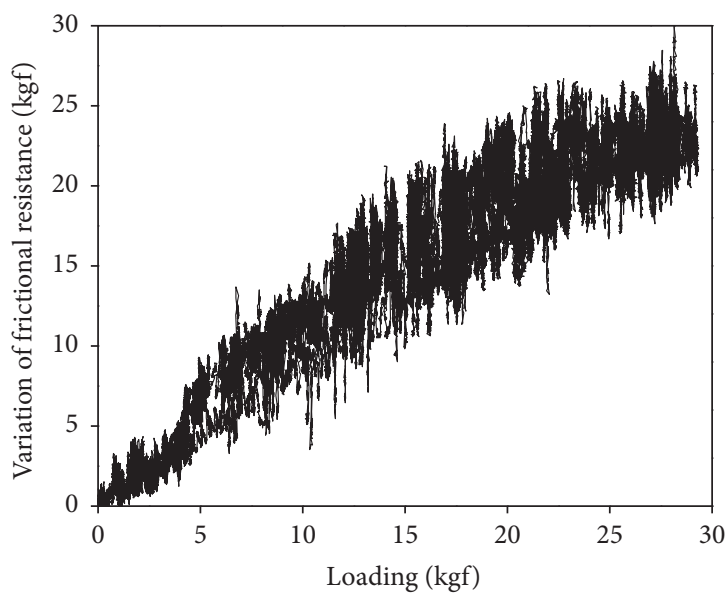

(f) $300 \mathrm{r} / \mathrm{min}$

Figure 8: Dynamic axial load.

the rotation drill string is $78 \%$ of that of the nonrotation drill string with ignoring the friction. The experimental method is employed to research the relationship between the critical buckling load of the rotation drill string in horizontal well and that of nonrotation drill string in this section. The critical buckling load of the rotation drill string in horizontal well is shown in Table 5.
The theoretical calculation results of the critical buckling load are shown in Table 6.

The sinusoidal buckling load and the spiral buckling load are calculated with the methods proposed by Mitchell and Jiang. The results show that the critical load of sinusoidal buckling calculated in this paper is similar as the results obtained in the literatures [10]. The experiments are carried 
TABLE 5: Experimental results of critical buckling load of the drill string.

\begin{tabular}{lcc}
\hline $\begin{array}{l}\text { Rotational } \\
\text { speed/(r/min) }\end{array}$ & $\begin{array}{c}\text { Sinusoidal critical } \\
\text { buckling } \\
\text { load/(kgf) }\end{array}$ & $\begin{array}{c}\text { Spiral critical } \\
\text { buckling } \\
\text { load/(kgf) }\end{array}$ \\
\hline 0 & 7.0 & 16.0 \\
50 & 7.0 & 14.0 \\
100 & 7.0 & 14.0 \\
150 & 6.8 & 14.0 \\
200 & 6.8 & 13.0 \\
250 & 6.8 & 13.0 \\
300 & 6.8 & 12.0 \\
\hline
\end{tabular}

TABLE 6: Theoretical results of the critical loads.

\begin{tabular}{lc}
\hline Spiral buckling load/(kgf) & Sinusoidal buckling load $/(\mathrm{kgf})$ \\
\hline$F_{\text {hel }}=4 \sqrt{2 E I q / r}$ & $F_{\mathrm{cr}}=2 \sqrt{E I q / r}$ \\
16.190 & 7.632 \\
\hline
\end{tabular}

out by adjusting the rotational speed of the drill string and the axial load in order to obtain the dynamic critical buckling load of the drill string. The friction curves in the condition of loading and unloading under different rotational speeds of the drill string are obtained. The static friction curve and dynamic friction curve with different speeds are shown in Figures 9 and 10.

The critical load of the sinusoidal buckling is basically the same with the different rotational speed. Therefore, the rotational speed has no effect on the critical load of the sinusoidal buckling in horizontal well. However, the critical load of the spiral buckling of the rotation drill string is obviously smaller than that of the nonrotation drill string. The critical load of the spiral buckling with rotation is about $86 \%$ of the critical buckling load of the nonrotation drill string as the rotational speed within the scope $(50 \mathrm{r} / \mathrm{min}-150 \mathrm{r} / \mathrm{min}$ ) while it is $81 \%$ of the critical buckling load on the nonrotation drill string when the rotational speed is $200 \mathrm{r} / \mathrm{min}-250 \mathrm{r} / \mathrm{min}$. And it is $75 \%$ when the rotational speed is $300 \mathrm{r} / \mathrm{min}$.

In short, the rotational speed of the drill string in horizontal well has no effect on the critical load of the sinusoidal buckling. The critical load of the spiral buckling, however, is reduced. Therefore, the rotation of drill string cannot be neglected in the study of the stability of drill string in horizontal well. High rotational speed will accelerate the failure of the drill string and shorten the service life of the drill string in engineering. The critical load of the drill string should be calculated accurately under different rotational speed so as to lengthen the service life of the drill string.

5.4. Rotational Speed Effects on Dynamic Buckling. The influence of the rotational speed on the motion status of the drill string in horizontal well is analyzed in this section. The curves of the dynamic characteristic in the numerical simulation and the experiment are shown in Figure 11.

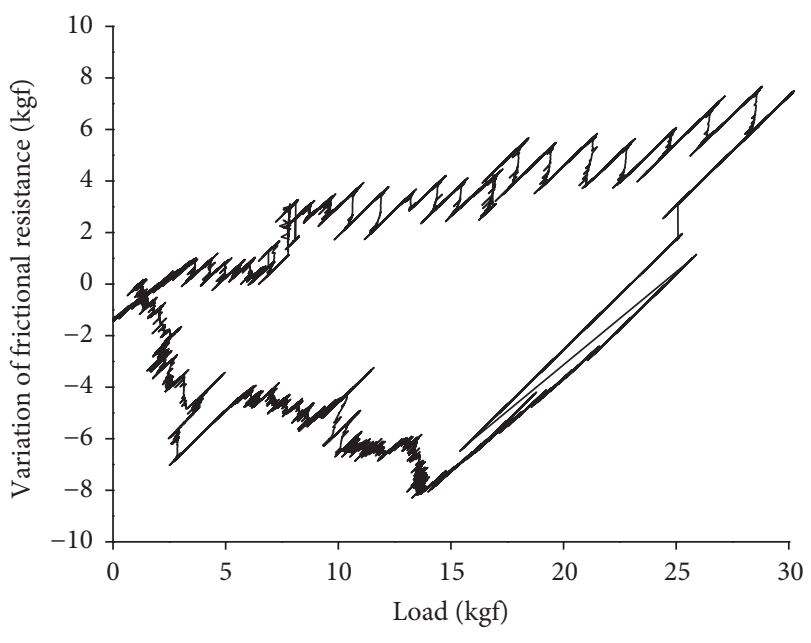

FIgURE 9: Curve of friction resistance (static).

The numerical simulations are basically in line with the experiments. Thus, the simulation results are proved to be reliable. With the increase of the rotational speed, the drill string is almost close to the bottom of the borehole wall at a low speed, leaving the bottom of the borehole wall at a higher speed. And the axis orbit exceeds the axis of the borehole; the drill string at the higher speed even collides the top of the borehole. Meanwhile, not only does the amplitude of the buckling increase, but the frequency of the vibration of the drill string increases. Therefore, for drilling operation, it is not appropriate to apply the extreme high speed for a long time, which will reduce the stability of the drill string and lead to the premature failure of the drill string.

5.5. Rotational Speed Effects on the Axis Orbit of the Drill String. The axis trajectory of the dynamic buckling in horizontal well under different rotational speeds is shown in Figure 12.

The buckling is mainly concentrated in the lower part of the borehole at a lower rotational speed, and the amplitude is also small. The drill string is still mainly in the lower part of the borehole when the speed is $150 \mathrm{r} / \mathrm{min}$. Meanwhile the amplitude obviously increases. When the speed is higher, not only does the amplitude continue to increase, but also the drill string beats the borehole wall as shown in Figure 12(e). The buckling is severer when the speed is $300 \mathrm{r} / \mathrm{min}$. The axis orbit of the drill string has been changed from the lower part of the borehole to the entire cross-section of the borehole, and the whirl motion after the snaking movement occurs.

Taken together, the drill string is always in the snaking state with the form of the sinusoidal buckling in the process of loading with the rotational speed in the range of $50 \mathrm{r} / \mathrm{min}-250 \mathrm{r} / \mathrm{min}$. The drill string is obviously transformed from a snaking motion with a sinusoidal buckling configuration into a whirl motion with a spiral buckling configuration in the process of loading with a rotational speed $300 \mathrm{r} / \mathrm{min}$. The whirl motion with the spiral buckling configuration can increase the friction between the drill string and the borehole wall and even cause the drill string locking. Therefore, the 


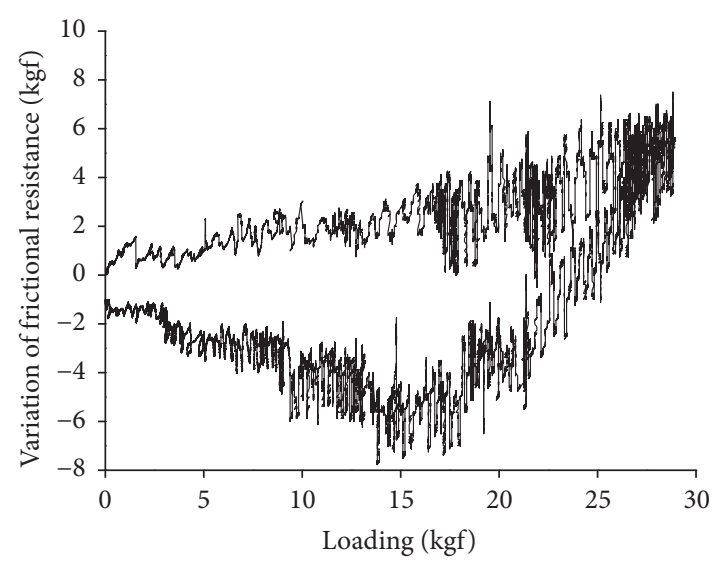

(a) $50 \mathrm{r} / \mathrm{min}$

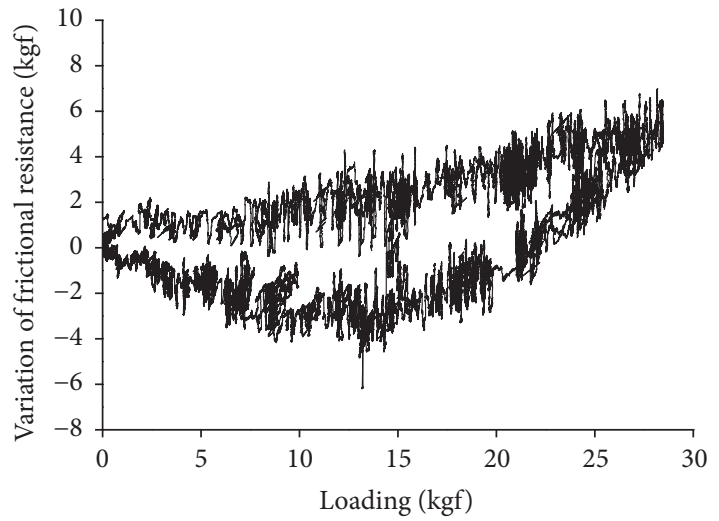

(c) $150 \mathrm{r} / \mathrm{min}$

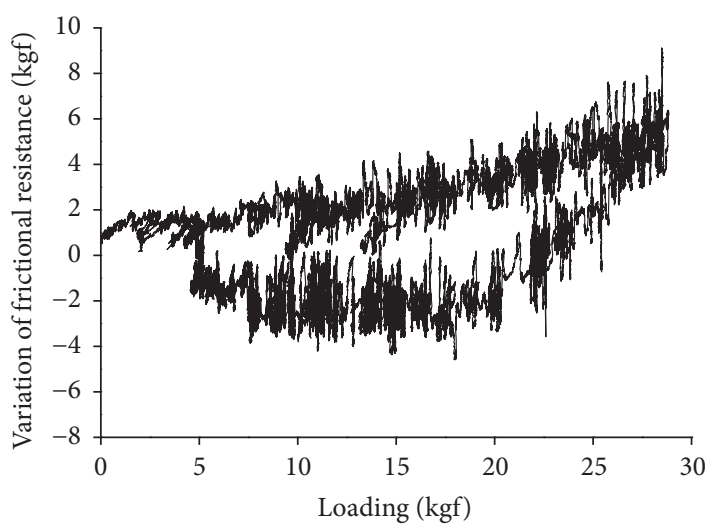

(e) $250 \mathrm{r} / \mathrm{min}$

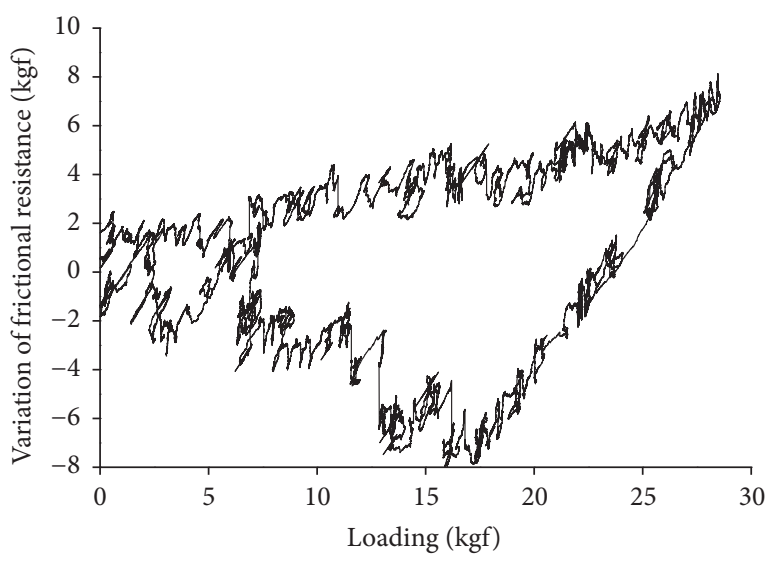

(b) $100 \mathrm{r} / \mathrm{min}$

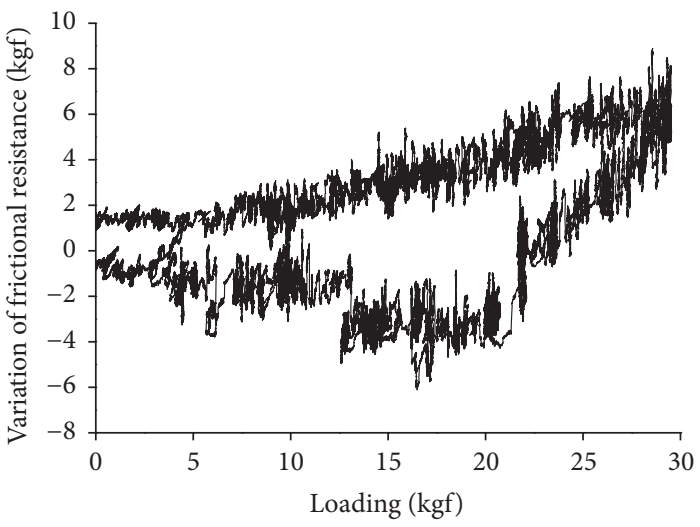

(d) $200 \mathrm{r} / \mathrm{min}$

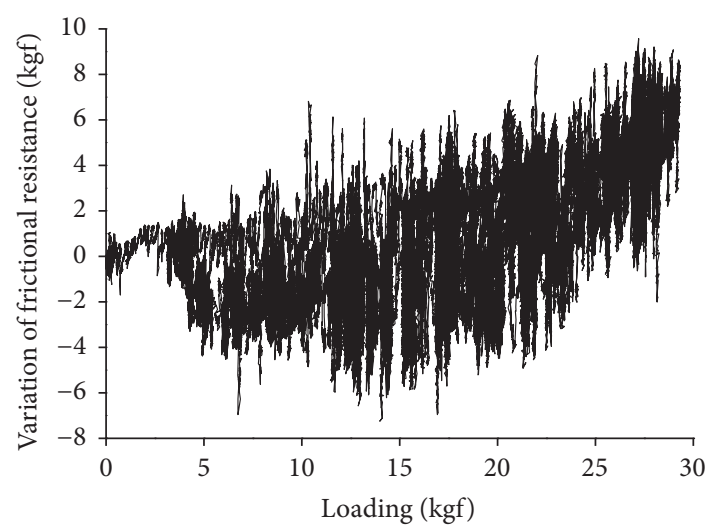

(f) $300 \mathrm{r} / \mathrm{min}$

Figure 10: Friction curve with different speeds (dynamic).

higher speed and axial load should be avoided to prevent selflocking phenomenon and the premature failure of the drill string.

\section{Conclusions}

(1) The rotational speed of the drill string in horizontal well has no effect on the critical load of the sinusoidal buckling with different rotational speeds. However, the critical load of the spiral buckling will reduce with the development of the rotational speed of the drill string. Thus, an excessive rotational speed will accelerate the drill string failure and shorten the service life of the drill string. The results can be used to calculate the critical load and the selection of the bottom hole assembly and the rotational speed of the drill string as predrilling.

(2) With the increase of the rotational speed, the vibration period of the drill string becomes smaller, and the amplitude of the dynamic buckling increases gradually. In other words, the stability of the drill string is gradually reduced. Therefore, 


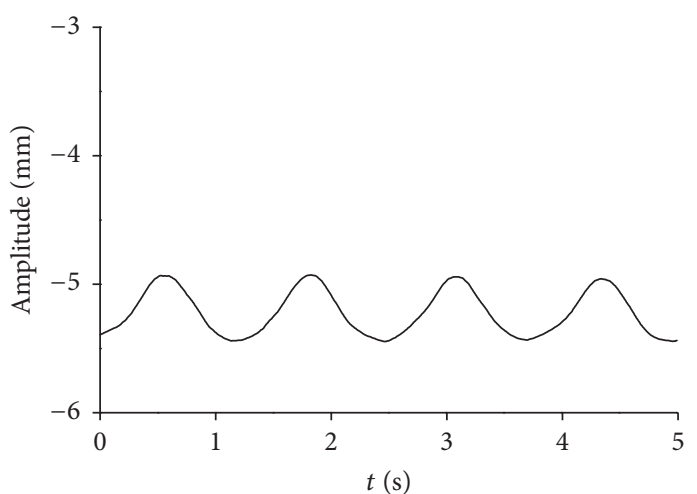

(a1) Numerical simulation (50 r/min)

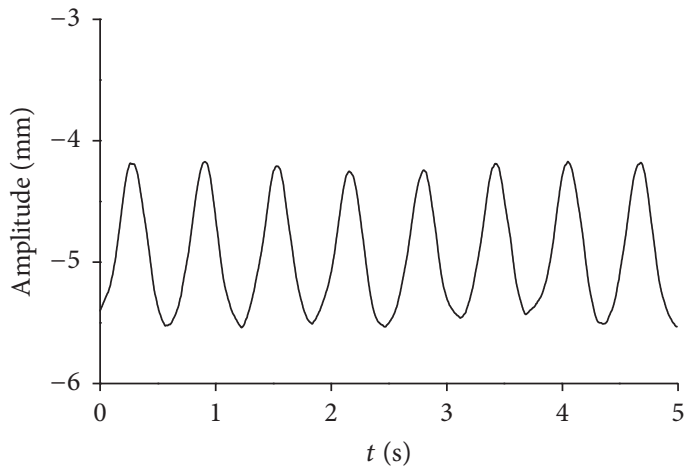

(b1) Numerical simulation (100 r/min)

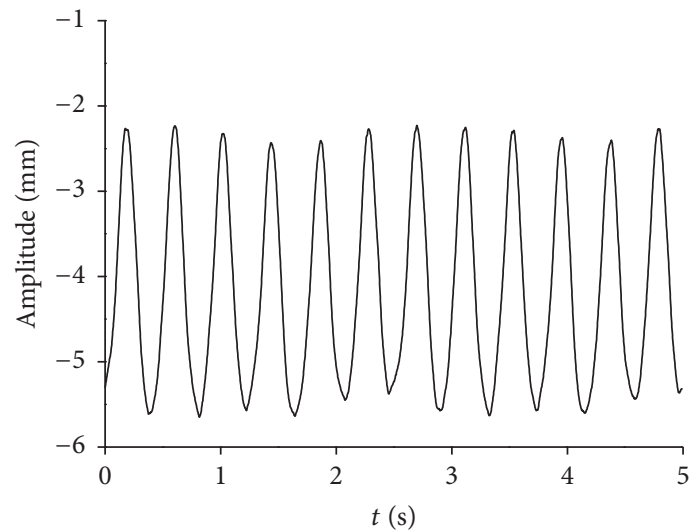

(c1) Numerical simulation ( $150 \mathrm{r} / \mathrm{min})$

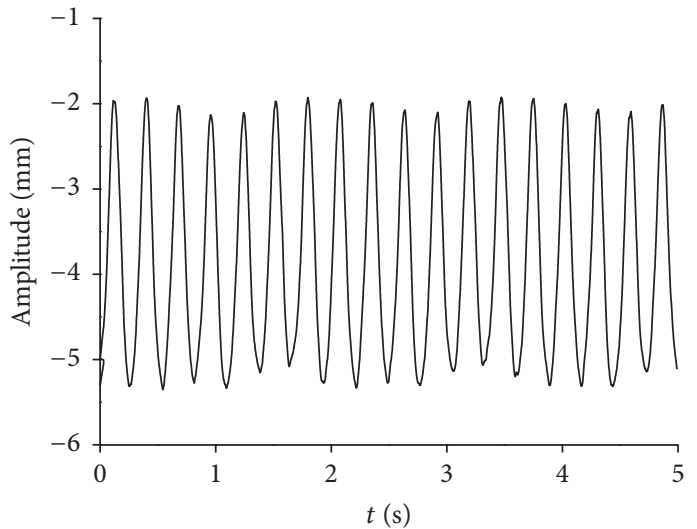

(d1) Numerical simulation (200 r/min)

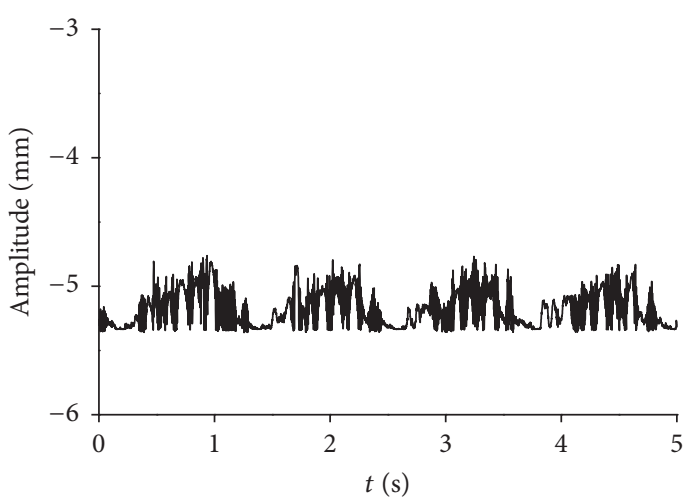

(a2) Experiment (50 r/min)

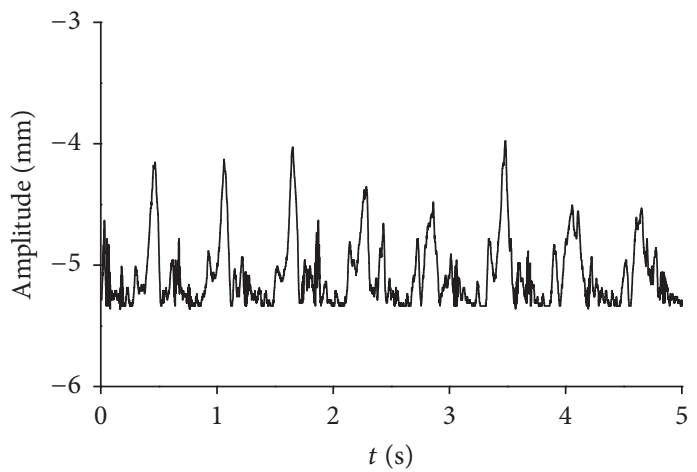

(b2) Experiment (100 r/min)

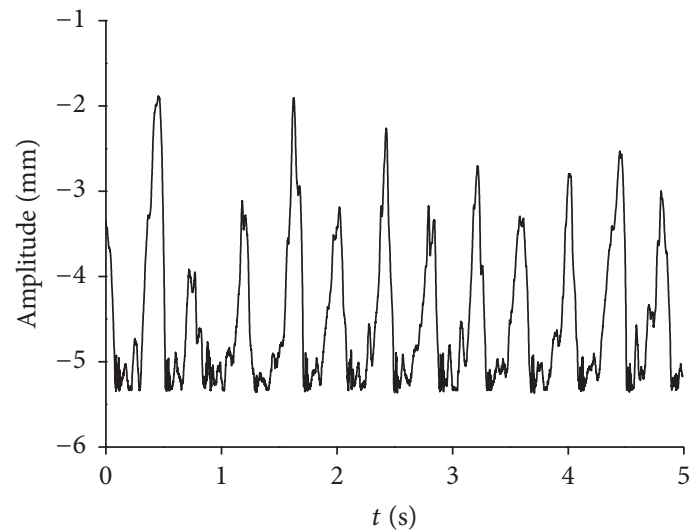

(c2) Experiment (150 r/min)

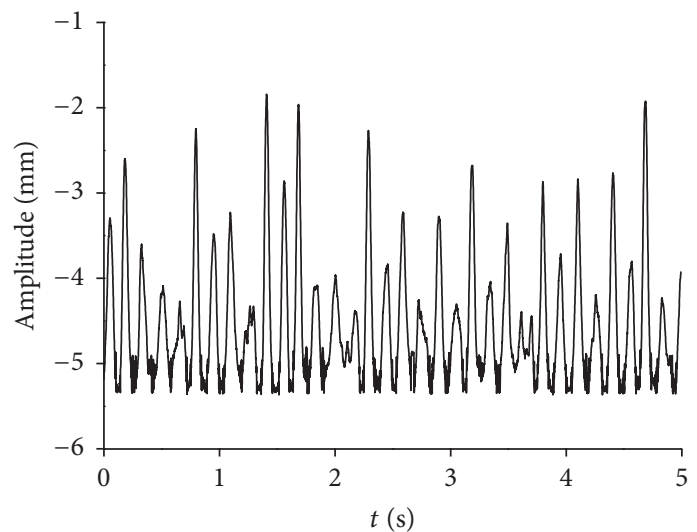

(d2) Experiment (200 r/min)

FIGURE 11: Continued. 


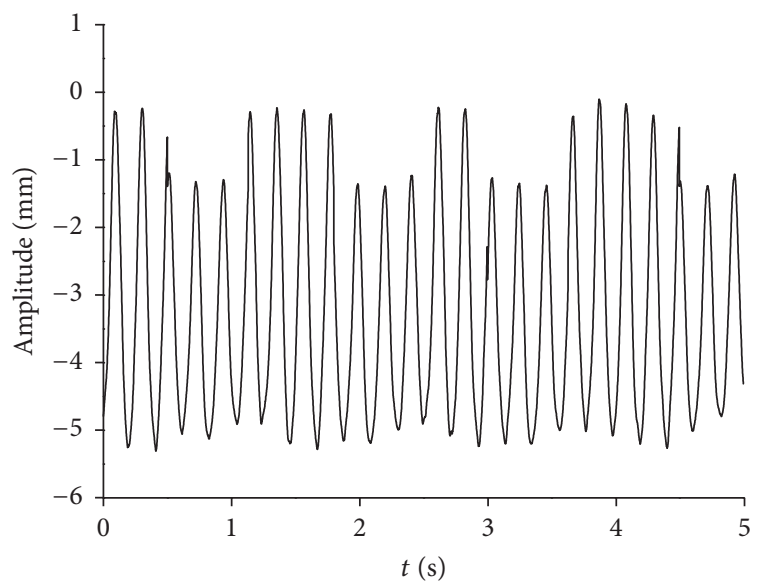

(e1) Numerical simulation (250 r/min)

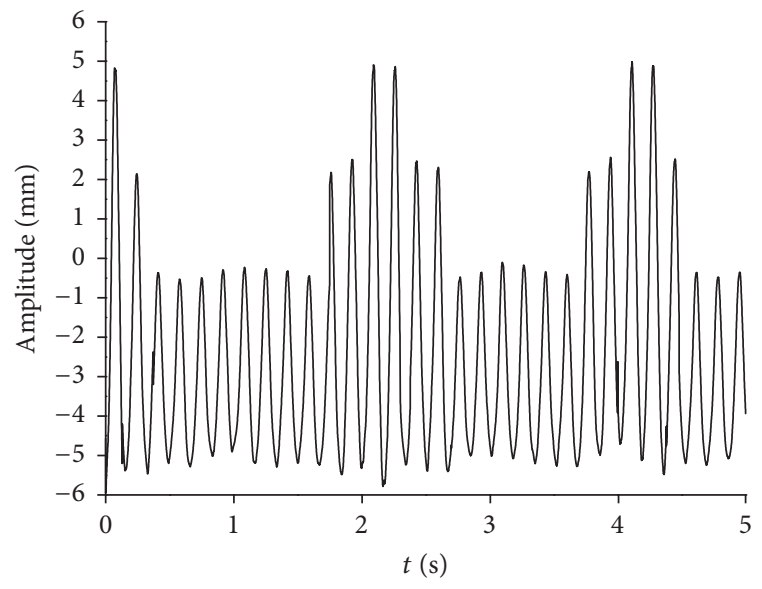

(f1) Numerical simulation (300 r/min)

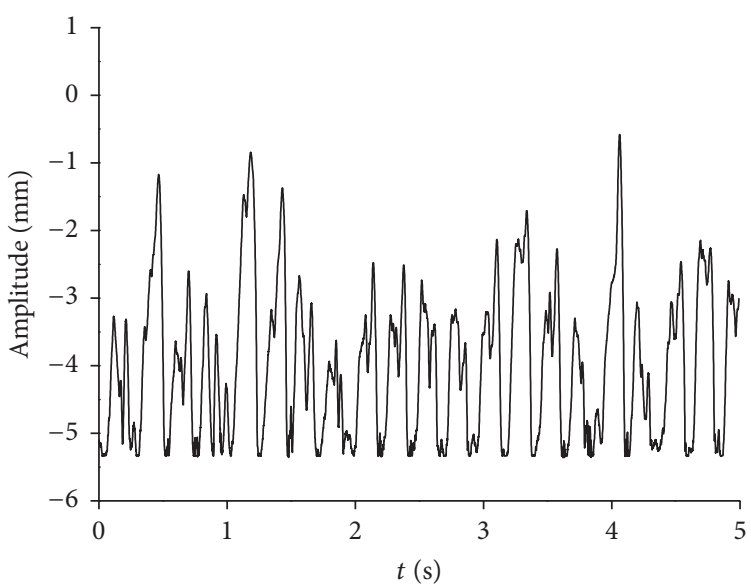

(e2) Experiment (250 r/min)

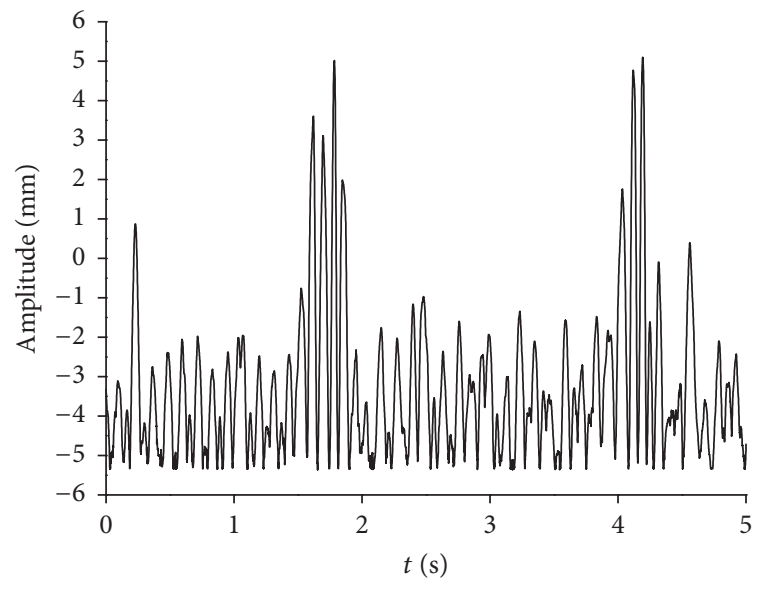

(f2) Experiment (300 r/min)

Figure 11: Dynamic buckling with different speeds.

it is not appropriate to apply the extreme high speed for a long time, which will reduce the stability of the drill string and lead to the premature failure of the drill string.

(3) The drill string is always in the snaking state with a sinusoidal buckling configuration in the process of loading at a lower rotational speed while in a whirl motion with a spiral buckling configuration at a higher rotational speed, which will cause the self-locking of the drill string.

\section{Nomenclature}

$a$ : Amplitude of static sinusoidal buckling

$a_{\max }$ : Maximum amplitude of the dynamic buckling

A: Cross-sectional area of the drill string

E: Youngster elastic modulus

$f$ : Sliding friction

$F$ : Axial compressive force

$F_{\mathrm{cr}}$ : Critical load of the spiral buckling of the drill string

$F_{\text {hel }}$ : Minimum critical load of the spiral buckling of the drill string
I: Axial memento of inertia

$I_{p}$ : Moment of inertia of $d x$

$\vec{J}$ : Angular momentum of a small section of the drill string

$L$ : $\quad$ Length of drill string

$m_{p}$ : Mass of $d x$

$\vec{M}$ : Moment vector

$N$ : Distributive normal contact force

$p$ : Wavelength of the spiral buckling

$p_{h}$ : Screw pitch of the buckling

$\vec{P}$ : Linear momentum of a small section of the drill string

$q$ : Weight per unit length of drill string

$r$ : Radial displacement

$r_{p}:$ Inner diameter of The drill string

$R_{p}:$ Outer diameter of The drill string

$T:$ Period of the dynamic buckling

$t$ : Time

$u_{a}$ : Displacement due to axial compression

$u_{b}$ : Displacement due to the lateral bending or buckling 


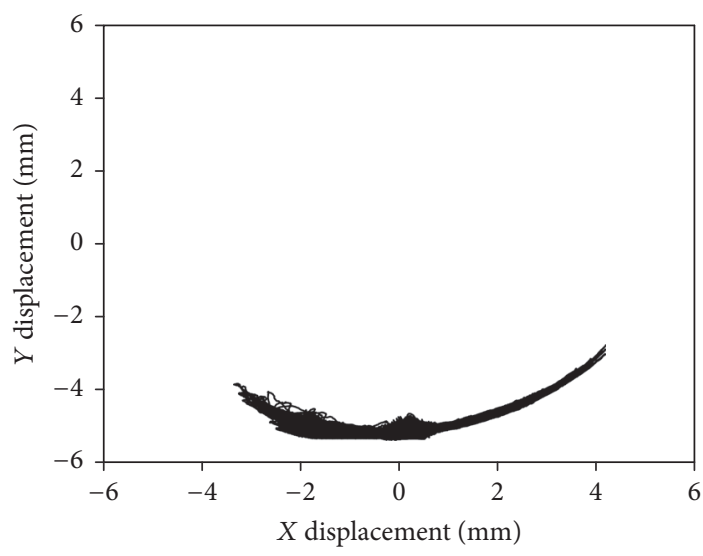

(a) $50 \mathrm{r} / \mathrm{min}$

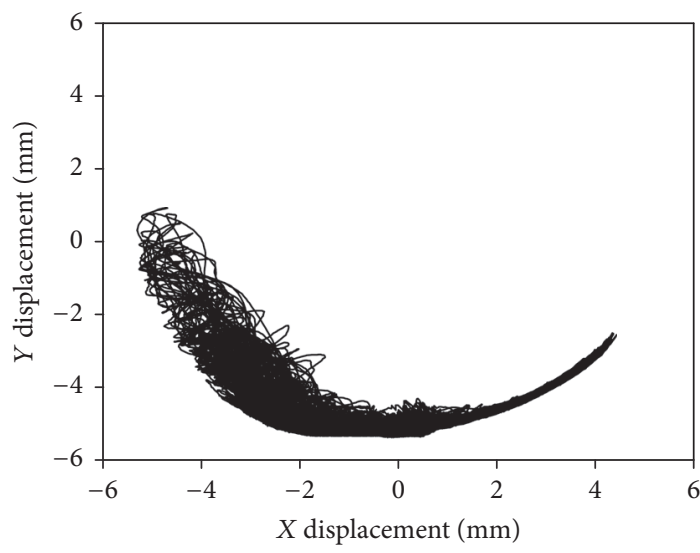

(c) $150 \mathrm{r} / \mathrm{min}$

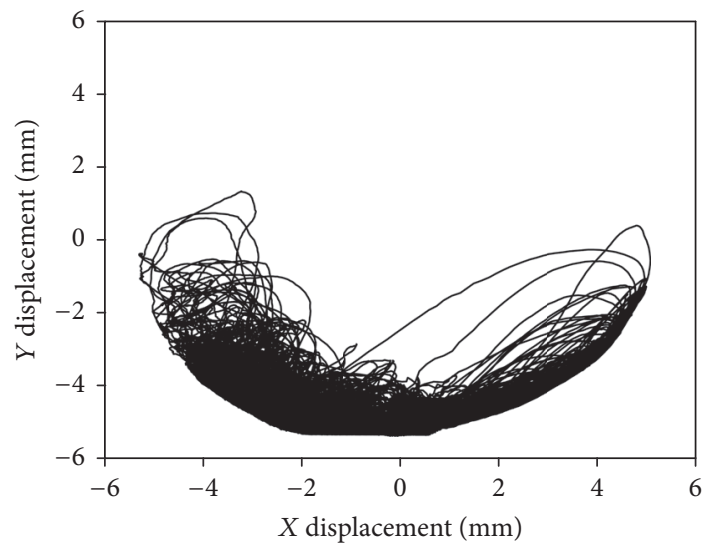

(e) $250 \mathrm{r} / \mathrm{min}$

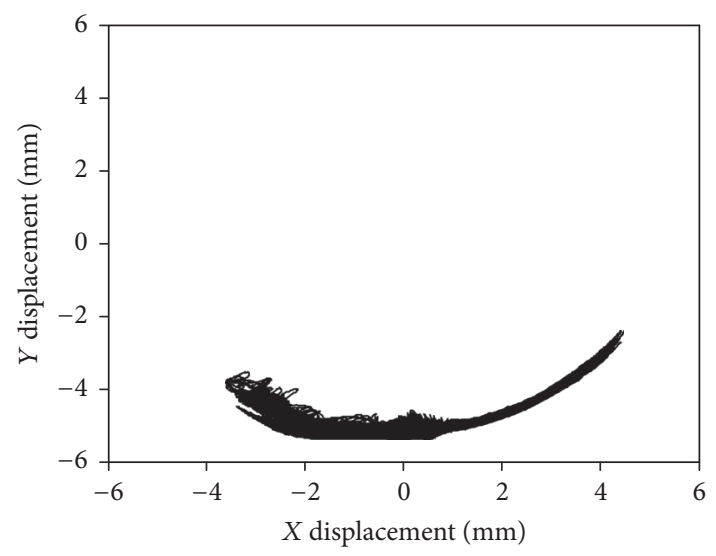

(b) $100 \mathrm{r} / \mathrm{min}$

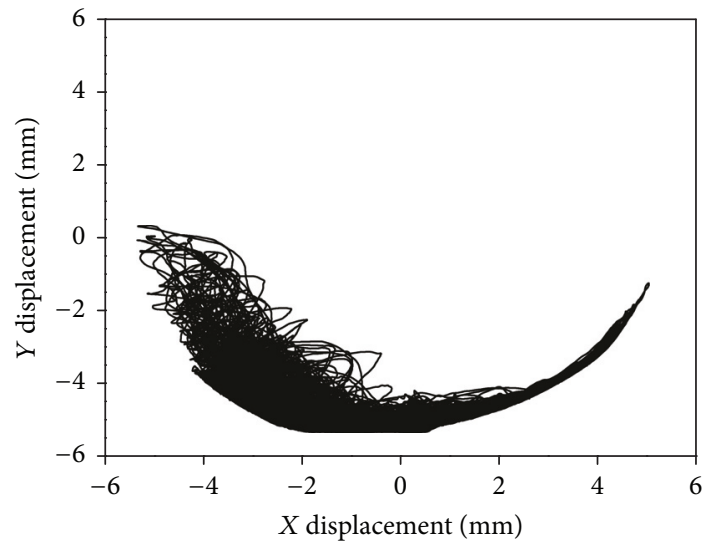

(d) $200 \mathrm{r} / \mathrm{min}$

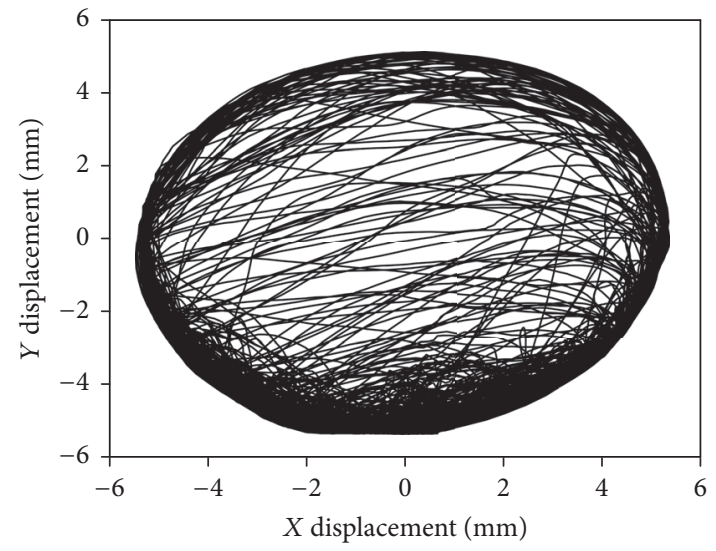

(f) $300 \mathrm{r} / \mathrm{min}$

FIGURE 12: Axis trajectory of the dynamic buckling at different speeds (dynamic).

$u_{x}$ : Axial displacement

$U_{b}$ : Elastic bending deformation energy

$v$ : Resultant velocity

$W_{q}$ : Work done by normal contact force

$x$ : Position along $x$-axis

$y$ : Position along $y$-axis

$z$ : $\quad$ Position along $z$-axis

$\theta:$ Angular displacement

$\omega$ : Rotational speed of the drill string

$\varepsilon$ : Dimensionless coefficient $\tau$ : Dimensionless time

$\Pi$ : Total energy.

\section{Conflicts of Interest}

The authors declare that they have no conflicts of interest.

\section{Acknowledgments}

This research is funded by the Natural Science Foundation of China (no. 11372071) and Northeast Petroleum University 
Innovation Foundation for Postgraduate (no. YJSCX2016022NEPU).

\section{References}

[1] M. T. Albdiry and M. F. Almensory, "Failure analysis of drillstring in petroleum industry: A review," Engineering Failure Analysis, vol. 65, pp. 74-85, 2016.

[2] J. M. Kamel and A. S. Yigit, "Modeling and analysis of stick-slip and bit bounce in oil well drillstrings equipped with drag bits," Journal of Sound and Vibration, vol. 333, no. 25, pp. 6885-6899, 2014.

[3] M. Hajianmaleki and J. S. Daily, "Critical-Buckling-Load assessment of drillstrings in different wellbores by use of the explicit finite-Element method," SPE Drilling \& Completion, vol. 29, no. 2, pp. 256-264, 2014.

[4] A. Lubinski, "A study of the buckling of rotary drilling strings," Drilling \& Production Practice, vol. 50, pp. 178-190, 1950.

[5] A. Lubinski, W. S. Althouse, and J. L. Logan, "Helical buckling of tubing sealed in packers," Journal of Petroleum Technology, vol. 14, pp. 655-670, 1962.

[6] R. Mitchell, "Buckling behavior of well tubing: The packers effect," SPE Journal, vol. 22, pp. 616-624, 1982.

[7] R. F. Mitchell, "Comprehensive analysis of buckling with friction," SPE Drilling \& Completion, vol. 11, no. 3, pp. 178-183, 1996.

[8] R. F. Mitchell, "Effects of well deviation on helical buckling," SPE Drilling \& Completion, vol. 12, no. 1, pp. 63-68, 1997.

[9] R. F. Mitchell, "Simple frictional analysis of helical buckling of tubing," SPE Drilling Engineering, vol. 1, no. 6, pp. 457-465, 1986.

[10] R. F. Mitchell, "The effect of friction on initial buckling of tubing and flowlines," SPE Drilling \& Completion, vol. 22, no. 2, pp. 112118, 2007.

[11] W. Huang, D. Gao, and Y. Liu, "A study of tubular string buckling in vertical wells," International Journal of Mechanical Sciences, vol. 118, pp. 231-253, 2016.

[12] D. Gao, F. Liu, B. Xu, and D. L. Gao, "Study on the buckling behavior of pipe string in crooked hole," Oil Drilling \& Production Technology, vol. 22, pp. 1-4, 2000.

[13] D. L. Gao, Down-Hole Tubular Mechanics and Its Applications, China University Petroleum Press, 2006.

[14] P. Wang, T. Yan, X. Bi, and S. Sun, "Fatigue life prediction of buckling string with cracks in horizontal wells of mining engineering," Advanced Materials Research, vol. 577, pp. 127-131, 2012.

[15] X. J. He, "Helical buckling and lock-up conditions for coiled tubing in curved wells," SPE Drilling \& Completion, vol. 10, no. 1, pp. 10-15, 1995.

[16] R. F. Mitchell, "The twist and shear of helically buckled pipe," SPE Drilling \& Completion, vol. 19, no. 1, pp. 20-28, 2004.

[17] S. Menand, H. Sellami, M. Tijani et al., "Buckling of tubulars in simulated field conditions," Society of Petroleum Engineers, vol. 24, pp. 276-285, 2013.

[18] R. Dawson and P. R. Paslay, "Drill pipe buckling in inclined holes," in Proceedings of the Drill Pipe Buckling in Inclined Holes, New Orleans, La, USA, 1982.

[19] F. J. Schuh, "The critical buckling force and stresses for pipe in inclined curved boreholes," in Proceedings of the SPE/IADC Drilling Conference, Amsterdam, Netherlands, 1991.

[20] J. Wu, H. C. Juvkam-wood, and R. Lu, "Preventing Helical buckling of pipes in extended research and horizontal wells," in Proceedings of the Energy-Source Technology Conference \& Exhibition, Houston, USA, 1993.

[21] P. R. Paslay and D. B. Bogy, "The stability of circular rod laterally constrained to be in contact with an inclined circular cylinder," Journal of Applied Mechanics, vol. 31, pp. 605-610, 1964.

[22] J. Wu and H. Juvkam-Wold, "Study of helical buckling of pipes in horizontal wells," Society of Petroleum Engineers, vol. 25, pp. 867-876, 1993.

[23] W. Y. Qiu, "Effect of coiled-tubing initial configuration on buckling behavior in a constant-curvature hole," SPE Journal, vol. 4, pp. 64-71, 1999.

[24] W. Qiu, S. Miska, and L. Volk, "Effect of coiled tubing (CT) initial configuration on buckling/bending behavior in straight deviated wells," in Proceedings of the Latin American and Caribbean Petroleum Engineering Conference, Rio de Janeiro, Brazil, 1997.

[25] D. L. Gao, F. W. Liu, and B. Y. Xu, "An analysis of helical buckling of long tubulars in horizontal wells," in Proceedings of the SPE International Oil and Gas Conference and Exhibition, Beijing, China, 1998.

[26] O. B. Duman, S. Miska, and E. Kuru, "Effect of tool joints on contact force and axial-force transfer in horizontal wellbores," SPE Drilling \& Completion, vol. 18, no. 3, pp. 267-274, 2003.

[27] O. Duman, S. Miska, and E. Kuru, "Effect of tool joints on contact force and axial force transfer in horizontal wellbores," in Proceedings of the SPE/IADC Middle East Drilling Technology Conference, Bahrain, 2001.

[28] T. Weltzin, B. Aas, E. Andreassen, and M. Lindland, "Measuring drill pipe buckling using continuous gyro challenges existing theories," in Proceedings of the IADC/SPE Asia Pacific Drilling Technology Conference and Exhibition, Indonesia, 2008.

[29] T. Weltzin, B. Aas, E. Andreassen, and M. Lindland, "Measuring drillpipe buckling using continuous gyro challenges existing theories," SPE Drilling \& Completion, vol. 24, no. 4, pp. 464-472, 2009.

[30] R. F. Mitchell and T. Weltzin, "Lateral buckling-The key to lockup," SPE Drilling \& Completion, vol. 26, no. 3, pp. 436-452, 2011.

[31] D. D. Shao, Z. C. Guang, X. Wei, and Y. C. Shi, "Experimental device of horizontal drillstring dynamics based on similitude principle," vol. 7, pp. 63-70, 2013. 


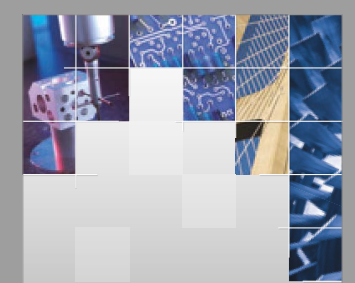

\section{Enfincering}
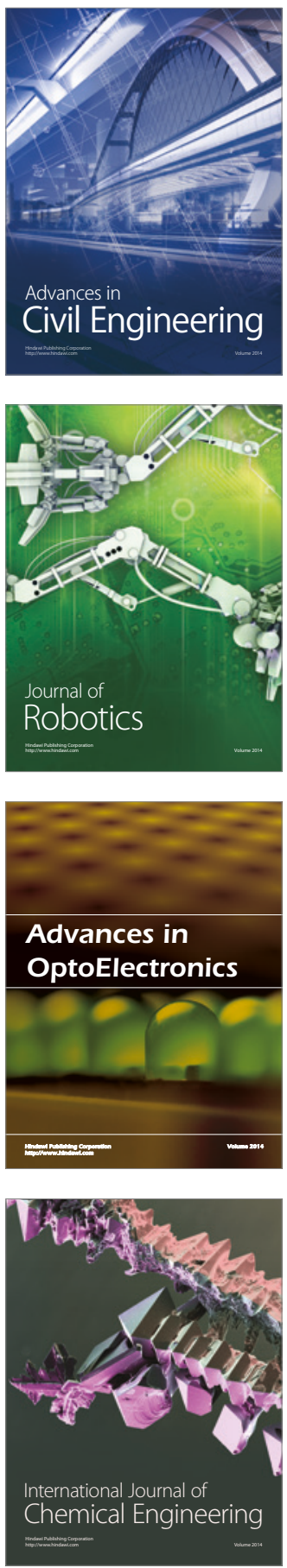

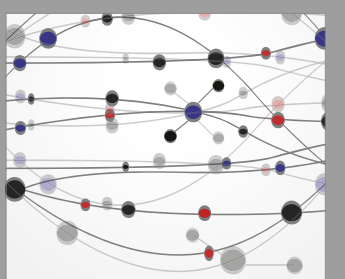

The Scientific World Journal

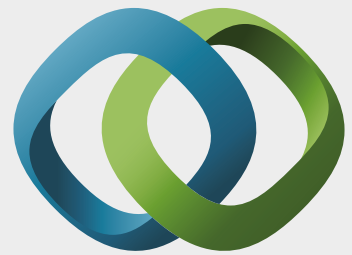

\section{Hindawi}

Submit your manuscripts at

https://www.hindawi.com
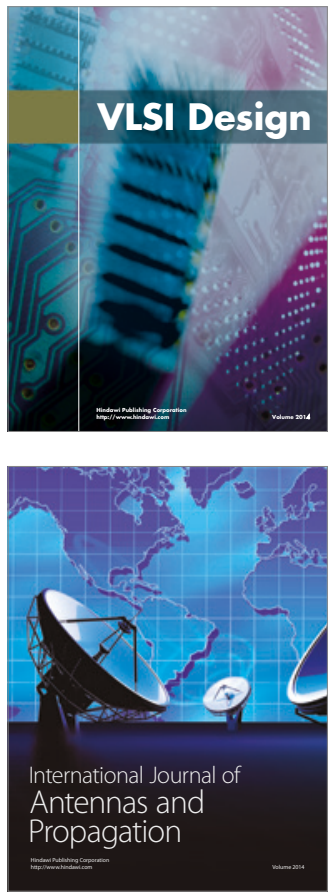

\section{Rotating}

Machinery
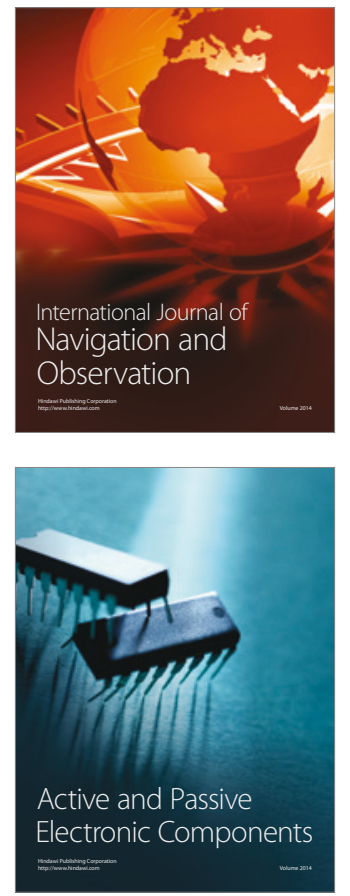
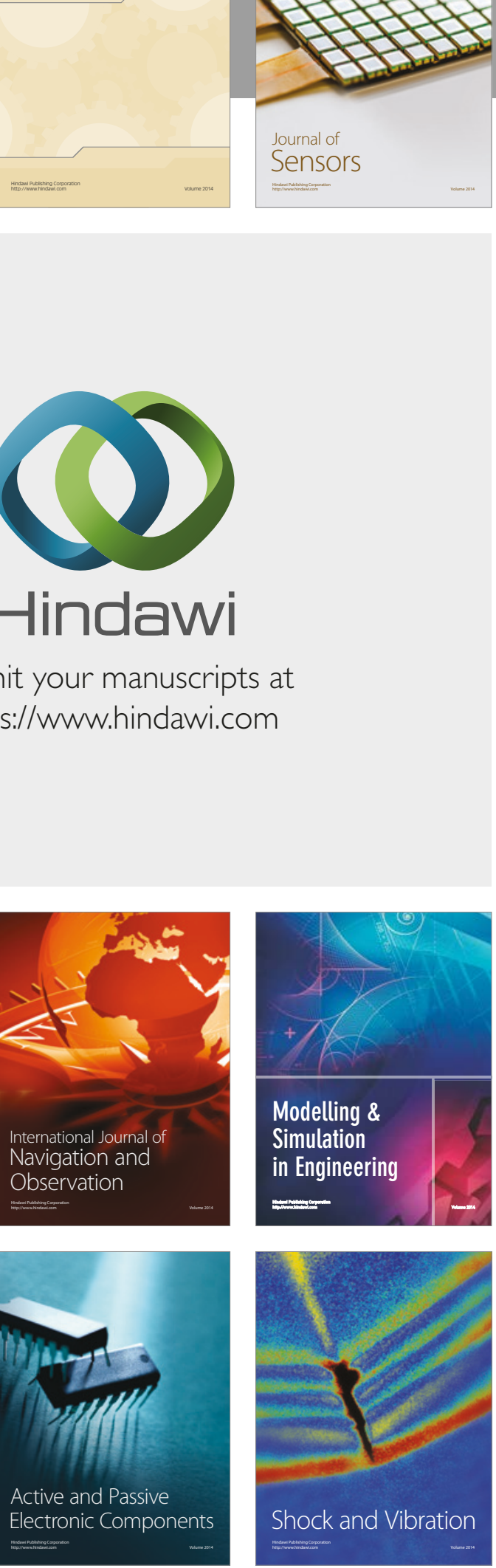
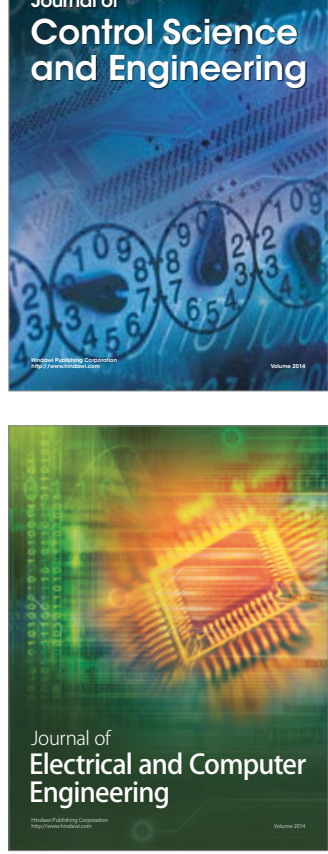

Distributed

Journal of

Control Science

and Engineering
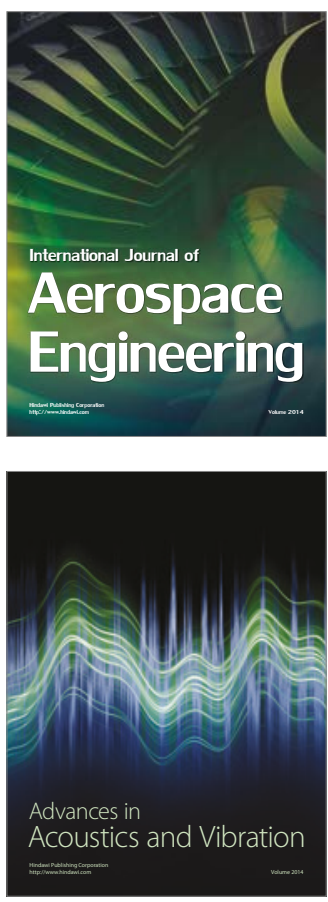

Sensor Networks 